NBER WORKING PAPER SERIES

\title{
OPTIMAL MONETARY POLICY WITH COLLATERALIZED HOUSEHOLD DEBT AND BORROWING CONSTRAINTS
}

\author{
Tommaso Monacelli \\ Working Paper 12470 \\ http://www.nber.org/papers/w12470 \\ NATIONAL BUREAU OF ECONOMIC RESEARCH \\ 1050 Massachusetts Avenue \\ Cambridge, MA 02138 \\ August 2006
}

This paper was prepared for the NBER Conference "Monetary Policy and Asset Prices", Chatam, MA, 5-6 May 2006. I would like to thank John Campbell and Hanno Lustig for very useful comments. The views expressed herein are those of the author(s) and do not necessarily reflect the views of the National Bureau of Economic Research.

(C)2006 by Tommaso Monacelli. All rights reserved. Short sections of text, not to exceed two paragraphs, may be quoted without explicit permission provided that full credit, including () notice, is given to the source. 
Optimal Monetary Policy with Collateralized Household Debt and Borrowing Constraints Tommaso Monacelli

NBER Working Paper No. 12470

August 2006

JEL No. E24, E44, E5

\begin{abstract}
$\underline{\text { ABSTRACT }}$
We study optimal monetary policy in an economy with nominal private debt, borrowing constraints and price rigidity. Private debt reflects equilibrium trade between an impatient borrower, who faces an endogenous collateral constraint, and a patient saver, who engages in consumption smoothing. Since inflation can positively affect borrower's net worth, monetary policy optimally balances the incentive to offset the price stickiness distortion with the one of marginally relaxing the borrower's collateral constraint. We find that the optimal volatility of inflation is increasing in three key parameters: (i) the borrower's weight in the planner's objective function; (ii) the borrower's impatience rate; (iii) the degree of price flexibility. In general, however, deviations from price stability are small for a small degree of price stickiness. In a two-sector version of our model, in which durable price movements can directly affect the ability of borrowing, the optimal volatility of (non-durable) inflation is more sizeable. In our context, and relative to simple Taylor rules, the Ramsey-optimal allocation entails a partial smoothing of real durable goods prices.
\end{abstract}

Tommaso Monacelli

Università Bocconi

IGIER

Via Salasco 5

20136 Milan

ITALY

tommaso.monacelli@unibocconi.it 
" Debt leverage of all types is often troublesome when one judges the stability of the economy. Should home prices fall, we would have reason to be concerned about mortgage debt".

\section{Introduction}

The sizeable increase in house prices combined with an unprecedented rise in household debt have been among the most important facts observed in several OECD countries in the last decade. In addition, the two facts are usually perceived as mutually reinforcing. The rise in house prices has induced households to increasingly extract equity from their accumulated assets thereby encouraging further borrowing against the realized capital gains. Dynamics of this sort have been considered important in sustaining the level of private spending in several countries, especially during the business cycle downturn of 2001. Figure 1 displays the dynamics of total private consumption and household mortgage debt in the US. Figure 2 displays the joint behavior of private consumption and of (an harmonized index of) house prices. It is clear that these three variables display a significant degree of comovement at the business cycle frequency.

Large part of the observed increase in household borrowing has been in the form of collateralized debt. Hence the role of durable goods - especially housing - as an instrument of collateralization has also increased over time. Figure 3 displays the evolution of mortgage debt (as a prototype form of secured debt) as a share of total outstanding household debt. This share has increased from about $60 \%$ in 1952 to about $75 \%$ in 2005 . If one were to consider also vehicles loans, the share of collateralized debt in the U.S. would rise to about $90 \% .^{2}$

While developments in the housing sector and institutional features in mortgage markets (e.g., prevalence of fixed vs. variable mortgage contracts, importance of equity with-

\footnotetext{
${ }^{1}$ Former Federal Reserve Chairman Greenspan's remarks at America's Community Bankers Annual Convention, Washington, D.C., October 19, 2004.

${ }^{2}$ Campbell and Hercowitz (2005), Aizcorbe, Kennickell and Moore (2003).
} 


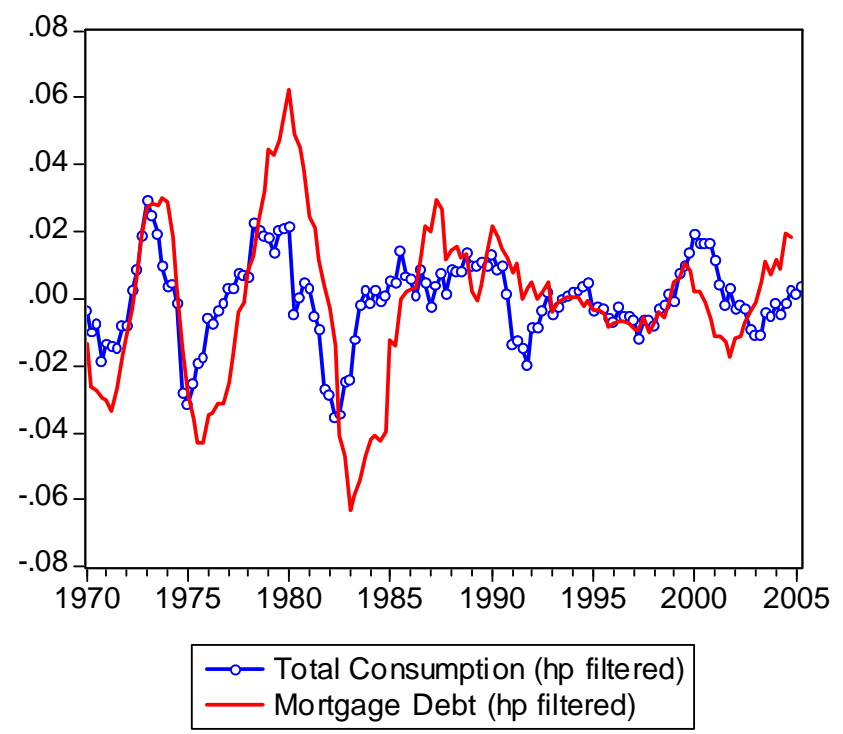

Figure 1: Consumption and Mortgage Debt

drawal, down-payment and refinancing rates) have become common vocabulary for monetary policymakers around the world, the same issues have received very scant attention in the recent normative analysis of monetary policy.

The monetary policy literature has soared in the last few years within the framework of the so-called New Neoclassical Synthesis (NNS). The NNS builds on microfounded models with imperfect competition and nominal rigidities, and has currently emerged as a workhorse paradigm for the normative analysis of monetary policy. ${ }^{3}$ However, in the NNS, the transmission mechanism of monetary policy remains limited to a typical real interest rate channel on aggregate demand. The latter channel ignores issues related to credit market imperfections, wealth effects linked to the evolution of asset prices, households' heterogeneity in saving rates and determinants of collateralized debt.

Principles of optimal monetary policy within the NNS revolve around the polar star of price stability. ${ }^{4}$ Consider the basic efficiency argument for price stability. Suppose, for the

\footnotetext{
${ }^{3}$ See, among many others, Goodfriend and King (1997), Woodford (2003), Clarida, Gali and Gertler (1999), King and Wolman (1999), Khan et al. (2003).

${ }^{4}$ In fact, much of the existing literature can be interpreted as studying the conditions under which
} 


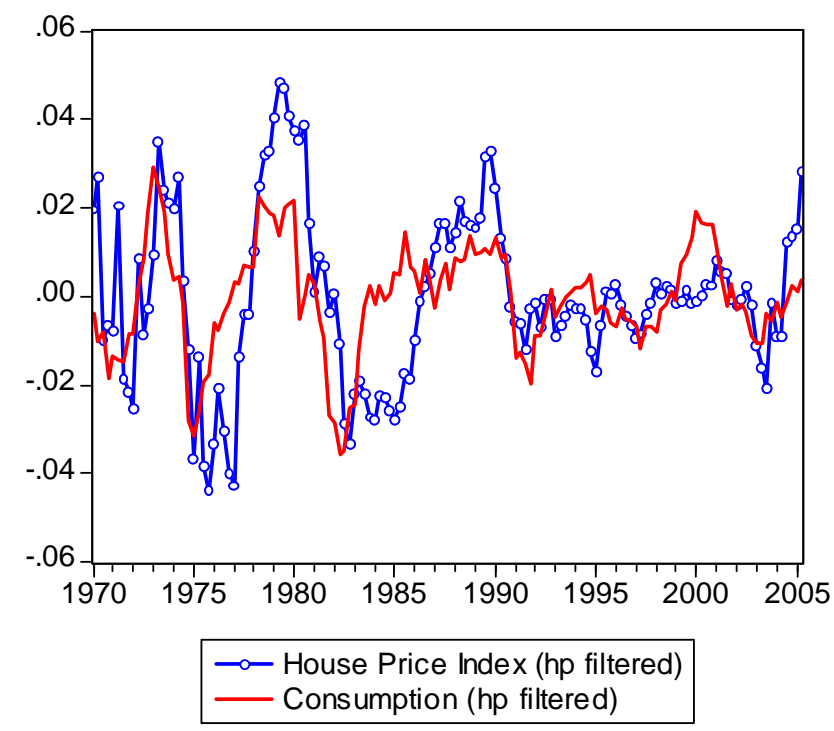

Figure 2: Consumption and House Prices

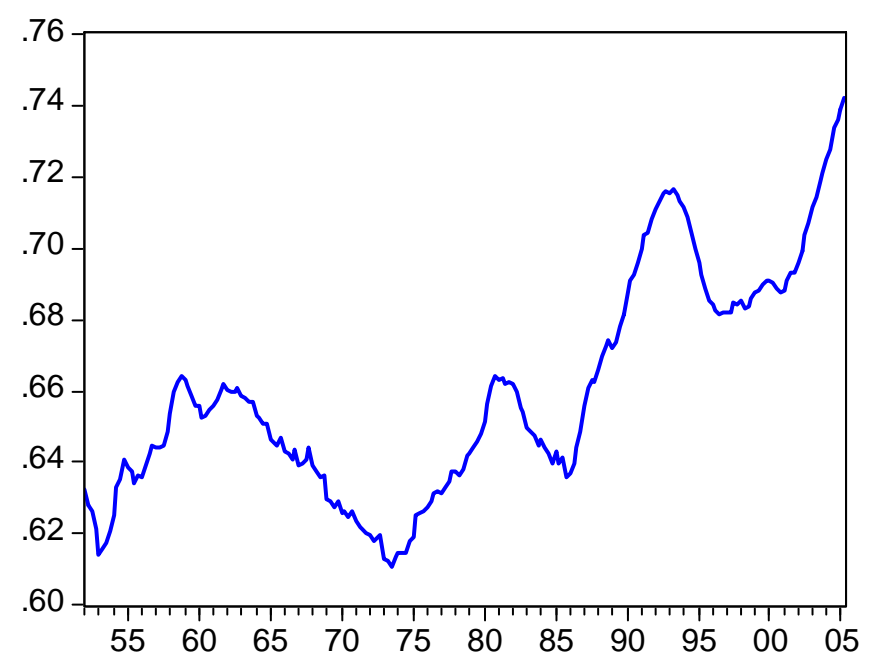

Figure 3: Mortgage Debt as a Share of Total Outstanding Household Debt. 
sake of exposition, that the economy experiences a positive productivity shock and that prices are completely rigid. Firms are constrained to comply with demand at that given price. Hence they react by raising markups and reducing labor demand. The stickiness of prices generates room for a procyclical monetary intervention to boost aggregate demand in line with the higher desired production. In turn this validates the strict stability of prices as an equilibrium choice by firms. In practice, this monetary policy intervention manages in eliminating the distortion induced by price stickiness.

Matters are different in our framework, characterized by two main features. First, households display heterogenous patience rates and therefore different marginal utilities of consumption (saving). Second, the more impatient agents face a collateral constraint on nominal borrowing. Both elements constitute a deviation from the standard representative agent model with free borrowing which is typical of the NNS. In that framework, by construction, debt is always zero in equilibrium.

To understand why these features may alter the baseline normative implication of price stability that emerges in the NNS, we emphasize two distinct dimensions. First, the role of nominal private debt per se. Second, the role of durable prices in affecting the ability of borrowing by endogenously altering the value of the assets that act as collateral.

Consider the role of debt first. If debt contracts are predetermined in nominal terms, inflation can directly affect household's net worth by reducing the real value of outstanding debt service. Thus inflation can have redistributive effects (from savers to borrowers). The key issue, then, is the extent to which a Ramsey-optimal policy would like to resort to this redistributive margin in equilibrium. Once again, consider a temporary rise in productivity. A constrained household (the borrower), whose marginal utility of current consumption exceeds the marginal utility of saving, would like to increase spending, and do so disproportionately more than an unconstrained agent (the saver), who engages in consumption smoothing. At the same time, in a model with collateral requirements, the borrower faces a wealth effect on labor supply. In fact, in order to sustain the surge in deviating from the price stability paradigm can be consistent with efficiency. See Woodford (2003) for a complete analysis. 
consumption, the borrower needs to optimally balance the purchasing of new debt with an increase in labor supply required to finance new collateral. The tighter the borrowing constraint, the more stringent the necessity of increasing labor supply. Importantly, monetary policy can exert an influence on this margin. By generating inflation, the monetary authority can positively affect borrower's net worth, thereby allowing the constrained household to increase consumption for any given level of work effort.

Thus the presence of nominal debt per se may constitute a motivation for deviating from a price stability prescription. In fact, and already previewing some of our key results, our analysis indicates that the optimal volatility of inflation is increasing in two parameters symbolizing heterogeneity: (i) the borrower's weight in the planner's objective function; (ii) the borrower's impatience rate (relative to the saver).

However, and due to the presence of price stickiness, inflation variability is costly. Hence monetary policy will have to optimally balance the incentive to offset the price stickiness distortion with the one of marginally affecting borrower's collateral constraint. Our results point out that, quantitatively, the incentive to offset the price stickiness distortion is predominant and that, already for a small degree of price stickiness, equilibrium deviations from price stability are small. ${ }^{5}$

Next consider the role of durable (asset) prices. In a way similar to the credit cycle effects exposed in Kiyotaki and Moore (1997) and Iacoviello (2005), movements in the real price of durables endogenously affect the borrowing limit and in turn consumption. The mechanism is simple. A rise in price of durables induces, ceteris paribus, a fall in the marginal value of borrowing (i.e., a softening of the borrowing constraint). This implies, for the borrower, a fall in the marginal utility of current (non-durable) consumption relative to the option of shifting consumption intertemporally (in other words, a violation of the Euler equation), which can be validated only by a rise in current consumption. In

\footnotetext{
${ }^{5}$ In this context with incomplete markets (in fact, one-period nominal debt is the only traded asset), there is an even more fundamental motive for inflation volatility, namely the incentive of the planner to "complete the markets", by rendering nominal debt state contingent. This motive, however, is strictly intertwined with the redistributive motive we emphasize here. In fact, no debt would be traded in the absence of heterogeneity, which in turn is the essential feature justifying redistribution.
} 
turn, the increased demand for borrowing further stimulates the demand for durables and its relative price, inducing a cycle effect that further boosts (non-durable) spending.

In an efficient equilibrium with free borrowing and lending, the borrower would indeed like (given his impatience) to expand borrowing to finance current consumption. Yet he/she would do so without resorting to an increase in demand for durables. Hence collateral limits per se induce inefficient movements in the relative price of durables. On the other hand, though, a strict stabilization of durable prices is largely detrimental for the borrower and would be inconsistent with the need of realizing sectoral relative price movements. As a result, the optimal policy balances the incentive to partially stabilize relative durable prices with the one of offsetting the stickiness in non-durable prices. In fact, in our simulations, a Ramsey-type policy emerges as an intermediate case between two extreme forms of Taylor-type interest rate rules: a rule that strictly stabilizes nondurable price inflation and a rule that strictly stabilizes the relative price of durables.

The existing literature related to this paper originates from the seminal work of Bernanke and Gertler (1989) (BG henceforth), who emphasize the role of collateral requirements in affecting aggregate fluctuations. In BG, collateral constraints are motivated by the presence of private information and limited liability. More recently, Kiyotaki and Moore (1997) (KM henceforth) build a general equilibrium model in which two categories of agents (borrowers and savers) trade private debt. Heterogeneity is introduced in the form of different patience rates. In KM, collateral requirements are motivated by the presence of limited enforcement, in a way similar to the approach followed here. Both BG and KM, despite some differences, share the central implication that the wealth of the borrower influences private spending. Iacoviello (2005) extends the work of KM to build a bridge with the recent New Keynesian monetary policy framework. In his analysis, the role of nominal debt and asset prices are central for the propagation of monetary policy shocks, but no normative aspect is analyzed. Campbell and Hercowitz (2005) analyze the implications for macroeconomic volatility of the relaxation of collateral requirements in the US (dated around 1980) in a general equilibrium environment. However, their real business cycle framework is not suitable for a study of monetary policy, and it abstracts 
from any role of asset prices. Recently, Erceg and Levin (2005) study optimal monetary policy in an economy with two sectors (durable and non durables) and similar to the one employed here. Their analysis, though, abstracts from any form of credit market imperfection.

\section{The Model}

The model builds on Iacoviello (2005) and Campbell and Hercowitz (2005). The economy is composed of two types of households, borrowers and savers, and two sectors - producing durable and non durable goods respectively - each populated by a large number of monopolistic competitive firms and by a perfectly competitive final goods producer. The borrowers differ from the savers in that they exhibit a lower patience rate and therefore a higher propensity to consume. ${ }^{6}$ Complementary to this assumption is the one that the borrowers face a collateral constraint. In fact, if agents were free to borrow and lend at the market interest rate, the borrowers would exhibit a tendency to accumulate debt indefinitely, rendering the steady state of the economy indeterminate. Peculiar to the borrowers is that their preferences are tilted towards current consumption. Formally, their marginal utility of current consumption exceeds the marginal utility of saving. As a result, in the face of a temporary positive shock to income, they do not act as consumption smoothers but tend instead to reduce saving. In this vein, the presence of household debt reflects equilibrium intertemporal trading between the two types of agents, with the savers acting as standard consumption-smoothers. ${ }^{7}$

\footnotetext{
${ }^{6}$ For early general equilibrium models with heterogenous impatience rates, see Becker (1980), Woodford (1986), Becker and Foias (1987), Krusell and Smith (1989). More recently, see Kiyotaki and Moore (1997), Iacoviello (2005), Campbell and Hercowitz (2005). Here we use the categories borrower/saver as synonimous of impatient and patient household respectively. Notice, however, that the fact that the relatively more impatient (patient) agent emerges as a borrower (saver) is an equilibrium phenomenon.

${ }^{7}$ Galí et al. (2006) also construct a model in which agents are heterogenous along the consumptionsmoothing dimension, and use it to analyze the effects of government spending shocks. In their framework, the non-smoothers are agents which are completely excluded from the possibility of borrowing (following Campbell and Mankiw (1989) those agents are named rule-of-thumb consumers). Hence, in that framework, private debt cannot emerge as an equilibrium phenomenon.
} 


\subsection{Final Good Producers}

In each sector $(j=c, d)$ a perfectly competitive final good producer purchases $Y_{j, t}(i)$ units of intermediate good $i$. The final good producer in sector $j$ operates the production function:

$$
Y_{j, t} \equiv\left(\int_{0}^{1} Y_{j, t}(i)^{\frac{\varepsilon_{j}-1}{\varepsilon_{j}}} d i\right)^{\frac{\varepsilon_{j}}{\varepsilon_{j}-1}}
$$

where $Y_{j, t}(i)$ is quantity demanded of the intermediate good $i$ by final good producer $j$, and $\varepsilon_{j}$ is the elasticity of substitution between differentiated varieties in sector $j$. Notice, in particular, that in the durable good sector $Y_{d, t}(i)$ refers to expenditure in the new durable intermediate good $i$ (rather than services). Maximization of profits yields demand functions for the typical intermediate good $i$ in sector $j$ :

$$
Y_{j, t}(i)=\left(\frac{P_{j, t}(i)}{P_{j, t}}\right)^{-\varepsilon_{j}} Y_{j, t} \quad j=c, d
$$

for all $i$. In particular, $P_{j, t} \equiv\left(\int_{0}^{1} P_{j, t}(i)^{1-\varepsilon_{j}} d i\right)^{\frac{1}{1-\varepsilon_{j}}}$ is the price index consistent with the final good producer in sector $j$ earning zero profits. ${ }^{8}$

\subsection{Borrowers/Workers}

The representative borrower consumes an index of consumption services of durable and non-durable final goods, defined as:

$$
X_{t} \equiv\left[(1-\alpha)^{\frac{1}{\eta}}\left(C_{t}\right)^{\frac{\eta-1}{\eta}}+\alpha^{\frac{1}{\eta}}\left(D_{t}\right)^{\frac{\eta-1}{\eta}}\right]^{\frac{\eta}{\eta-1}}
$$

where $C_{t}$ denotes consumption services of the final non-durable good, $D_{t}$ denotes services from the stock of the final durable good at the end of period t, $\alpha$ is the share of durable goods in the composite consumption index and $\eta \geq 0$ is the elasticity of substitution between services of non-durable and durable goods. In the case $\eta \rightarrow 0$ non-durable

\footnotetext{
${ }^{8}$ Hence the problem of the final good producer $j$ is: $\max P_{j, t} Y_{j, t}-\int_{0}^{1} P_{j, t}(i) Y_{j, t}(i) d i$ subject to $(1)$.
} 
consumption and durable services are perfect complements, whereas if $\eta \rightarrow \infty$ the two services are perfect substitutes.

The borrower maximizes the following utility program

$$
\mathcal{W}_{0} \equiv E_{0}\left\{\sum_{t=0}^{\infty} \beta^{t} U\left(X_{t}, N_{t}\right)\right\}
$$

subject to the sequence of budget constraints (in nominal terms):

$$
P_{c, t} C_{t}+P_{d, t}\left(D_{t}-(1-\delta) D_{t-1}\right)+R_{t-1} B_{t-1} \leq B_{t}+W_{t} N_{t}+T_{t}
$$

where $B_{t}$ is end-of-period t nominal debt, and $R_{t-1}$ is the nominal lending rate on loan contracts stipulated at time $t-1$. Furthermore, $W_{t}$ is the nominal wage, $N_{t}$ is labor supply and $T_{t}$ are net government transfers. Labor is assumed to be perfectly mobile across sectors, implying that the nominal wage rate is common across sectors.

In real terms (units of non-durable consumption), (5) reads:

$$
C_{t}+q_{t}\left(D_{t}-(1-\delta) D_{t-1}\right)+\frac{R_{t-1} b_{t-1}}{\pi_{c, t}} \leq b_{t}+\frac{W_{t}}{P_{c, t}} N_{t}+\frac{T_{t}}{P_{c, t}}
$$

where $q_{t} \equiv \frac{P_{d, t}}{P_{c, t}}$ is the relative price of the durable good, and $b_{t} \equiv \frac{B_{t}}{P_{c, t}}$ is real debt. The left hand side of (6) denotes uses of funds (durable and non-durable spending plus real debt service), while the right hand side denotes available resources (new debt, real labor income and transfers). An important feature of (6), which follows from debt contracts being predetermined in nominal terms, is that (non-durable) inflation can affect borrower's net worth. Hence, for given outstanding debt, a rise in inflation lowers the current real burden of debt repayments.

Later we will work with the following specification of the utility function

$$
U\left(X_{t}, N_{t}\right)=\log \left(X_{t}\right)-\frac{v}{1+\varphi} N_{t}^{1+\varphi}
$$

where $\varphi$ is the inverse elasticity of labor supply and $v$ is a scale parameter. ${ }^{9}$

\footnotetext{
${ }^{9}$ Notice that we abstract from an explicit role for money. Along the lines of Woodford (2003, chp. 2),
} 
Collateral Constraint Private borrowing is subject to a limit. We assume that the whole stock of debt is collateralized. The borrowing limit is tied to the value of the durable good stock:

$$
B_{t} \leq(1-\chi) D_{t} P_{d, t}
$$

where $\chi$ is the fraction of the durable stock value that cannot be used as a collateral.

In general, one can broadly think of $\chi$ as the down payment rate, or the inverse of the loan-to-value ratio, and therefore an indirect measure of the tightness of the borrowing constraint. ${ }^{10}$ Jappelli and Pagano (1989) provide evidence on the presence of liquidity constrained agents by linking their share to more structural features of the credit markets. In particular, they find that the share of liquidity constrained agents is larger in countries in which a measure of the loan-to-value ratio is lower. ${ }^{11}$

Notice that movements in the durable good price directly affect the ability of borrowing. It is widely believed that the recent rise in house prices in the US has induced households to increasingly extract equity from their accumulated assets thereby encouraging further borrowing against their realized capital gains. This link between asset price fluctuations and ability of borrowing has presumably played an important role in determining households' spending patterns during the recent business cycle evolution. ${ }^{12}$

one can think of the present economy as a cashless limit of a money-in-the-utllity model, in which the weight of real money balances in utility is negligible. Our maintained assumption is that the monetary authority can directly control the short-run nominal interest rate. This allows us to abstract from any monetary transaction friction driving the optimal policy prescription towards the Friedman rule.

\footnotetext{
${ }^{10}$ Notice, though, that $\chi=0$ does not correspond to a situation in which the borrowing contraint is absent. That situation would obtain only in the case in which heterogeneity in patience rates were assumed away. See more on this point below.

${ }^{11}$ The form of the collateral constraint has been deliberately kep simple to facilitate the analysis. However, there are at least two important dimensions that are neglected here. First, incorporating an explicit mortgage refinancing choice. In the US, in the last few years, the ability of extract equity has worked primarily through refinancing decisions linked to the downward trend in nominal interest rates. Second, a distinction betwee fixed and variable rate mortgage contracts. For a positive analysis of these issues see Calza, Monacelli and Stracca (2006).

${ }^{12}$ For instance, Alan Greenspan's view is summarized by the following excerpt: "Among the factors contributing to the strength of spending and the decline in saving have been developments in housing
} 
We assume that, in a neighborhood of the deterministic steady state, equation (5) is always satisfied with equality. ${ }^{13}$ We can then rewrite the collateral constraint in real terms (i.e., in units of non-durable consumption) as follows:

$$
b_{t}=(1-\chi) q_{t} D_{t}
$$

Given $\left\{b_{-1}, D_{-1}\right\}$, the borrower chooses $\left\{N_{t}, b_{t}, D_{t}, C_{t}\right\}$ to maximize (4) subject to (6) and (8). By defining $\lambda_{t}$ and $\lambda_{t} \psi_{t}$ as the multipliers on constraints (6) and (8) respectively, and $U_{x, t}$ as the marginal utility of a generic variable $x$, efficiency conditions read:

$$
\begin{gathered}
\frac{-U_{n, t}}{U_{c, t}}=\frac{W_{t}}{P_{c, t}} \\
U_{c, t}=\lambda_{t} \\
U_{c, t} q_{t}=U_{d, t}+\beta(1-\delta) E_{t}\left\{U_{c, t+1} q_{t+1}\right\}+U_{c, t}(1-\chi) \psi_{t} q_{t} \\
\psi_{t}=1-\beta E_{t}\left\{\frac{U_{c, t+1}}{U_{c, t}} \frac{R_{t}}{\pi_{c, t+1}}\right\}
\end{gathered}
$$

Equations (9) and (10) are standard. Respectively, they state that the marginal rate of substitution between consumption and leisure is equalized to the real wage (in units of ND consumption) and that the marginal utility of income is equalized to the marginal utility of consumption. Equation (11) is an intertemporal condition on durable demand. It

markets and home finance that have spurred rising household wealth and allowed greater access to that wealth. The rapid rise in home prices over the past several years has provided households with considerable capital gains (...)" (Congress Testimony, February 2005).

${ }^{13}$ This assumption is obviously not uncontroversial. Ideally one would like a model in which the borrowers may be free to choose to hit the borrowing limit only occasionally. Hence our assumption remains valid only to the extent that we consider small fluctuations around the relevant deterministic steady state (see more on this below), so that standard log-linearization techniques may still be applied. This can be assured by specifying disturbance processes of sufficiently small amplitude. 
requires the borrower to equate the marginal utility of current (non-durable) consumption to the marginal gain of durable services. The latter depends on three components: i) the direct utility gain of an additional unit of durable $U_{d, t}$; ii) the expected utility stemming from the possibility of expanding future consumption by means of the realized resale value of the durable purchased in the previous period, $\beta(1-\delta) E_{t}\left\{U_{c, t+1} q_{t+1}\right\}$; iii) the marginal utility of relaxing the borrowing constraint $U_{c, t}(1-\chi) \psi_{t} q_{t}$. Notice that, in the absence of borrowing constraints (i.e., $\psi_{t}=0$ ), the latter component drops out. Intuitively, if $\psi_{t}$ rises the borrowing constraint binds more tightly (i.e., the marginal gain of relaxing the constraint is larger) and therefore the marginal gain of acquiring an additional unit of durable (which, once used as collateral, allows to expand borrowing) is higher.

The interpretation of $\psi_{t}$ is more transparent from equation (12), which is a modified version of an Euler consumption condition. Indeed it reduces to a standard intertemporal condition in the case of $\psi_{t}=0$ for all $t$. Alternatively, it has the interpretation of an asset price condition. In fact, the marginal value of additional borrowing (the left hand side $\psi_{t}$ ) is tied to a payoff (right hand side) that captures the deviation from a standard Euler equation. Consider, for the sake of argument, $\psi_{t}$ rising from zero to a positive value. This implies, from (12), that $U_{c, t}>\beta E_{t}\left\{U_{c, t+1} \frac{R_{t}}{\pi_{c, t+1}}\right\}$. In other words, the marginal utility of current consumption exceeds the marginal utility of saving, i.e., the marginal gain of shifting one unit of consumption intertemporally. The higher $\psi_{t}$, the higher the net marginal benefit of purchasing the durable asset, which allows, by marginally relaxing the borrowing constraint, to purchase additional current consumption.

\subsection{Savers}

The economy is composed of a second category of consumers, labeled savers. They differ from the borrowers in the fact that they have a higher patience rate. In addition, we assume that the representative saver is the owner of the monopolistic firms in each sector. The saver does not supply labor. Saver's utility can be written: 


$$
E_{0}\left\{\sum_{t=0}^{\infty} \gamma^{t} \widetilde{U}\left(\widetilde{C}_{t}, \widetilde{D}_{t}\right)\right\}
$$

Importantly, preferences are such that the saver discounts the future more heavily than the borrower, hence $\gamma>\beta$. The saver's sequence of budget constraints reads (in nominal terms):

$$
P_{c, t} \widetilde{C}_{t}+P_{d, t}\left(\widetilde{D}_{t}-(1-\delta) \widetilde{D}_{t-1}\right)+R_{t-1} \widetilde{B}_{t-1} \leq \widetilde{B}_{t}+\widetilde{T}_{t}+\sum_{j} \widetilde{\Gamma}_{j, t}
$$

where $\widetilde{C}_{t}$ is saver's non-durable consumption, $\widetilde{D}_{t}$ is the saver's utility services from the stock of durable goods, $\widetilde{B}_{t}$ is end-of-period t nominal debt (credit), $\widetilde{T}_{t}$ are net government transfers and $\widetilde{\Gamma}_{j, t}$ are nominal profits from the holding of monopolistic competitive firms in sector $j$.

The efficiency conditions for this program are a standard Euler equation:

$$
\widetilde{U}_{c, t}=\gamma E_{t}\left\{\widetilde{U}_{c, t+1} \frac{R_{t}}{\pi_{c, t+1}}\right\}
$$

and a durable demand condition (in the absence of borrowing constraints)

$$
q_{t} \widetilde{U}_{c, t}=\widetilde{U}_{d, t}+\gamma(1-\delta) E_{t}\left\{\widetilde{U}_{c, t+1} q_{t+1}\right\}
$$

In this case, being a permanent-income consumer, the saver will equate the marginal rate of substitution between durable and non-durable consumption exactly to the standard user cost expression prevailing in the absence of borrowing constraints.

\subsection{Production and Pricing of Intermediate Goods}

A typical intermediate good firm $i$ in sector $j$ hires labor (supplied by the borrowers) to operate a linear production function:

$$
Y_{j, t}(i)=A_{j, t} N_{j, t}(i)
$$


where $A_{j, t}$ is a productivity shifter common to all firms in sector $j$. Each firm $i$ has monopolistic power in the production of its own variety and therefore has leverage in setting the price. In so doing it faces a quadratic cost equal to $\frac{\vartheta_{j}}{2}\left(\frac{P_{j, t}(i)}{P_{j, t-1}(i)}-1\right)^{2}$, where the parameter $\vartheta_{j}$ measures the degree of sectoral nominal price rigidity. The higher $\vartheta_{j}$ the more sluggish is the adjustment of nominal prices in sector $j$. In the particular case of $\vartheta_{j}=0$, prices are flexible.

The problem of each monopolistic firm is to choose the sequence $\left\{N_{j, t}(i), P_{j, t}(i)\right\}_{t=0}^{\infty}$ in order to maximize expected discounted nominal profits:

$$
E_{0}\left\{\sum_{t=0}^{\infty} \Lambda_{j, t}\left(P_{j, t}(i) Y_{j, t}(i)-W_{t} N_{j, t}(i)-\frac{\vartheta_{j}}{2}\left(\frac{P_{j, t}(i)}{P_{j, t-1}(i)}-1\right)^{2} P_{j, t}\right)\right\}
$$

subject to (17). In (18), $\Lambda_{j, t} \equiv \gamma E_{t}\left\{\frac{\widetilde{\lambda}_{t+1}}{\widetilde{\lambda}_{t}}\right\}$ is the saver's stochastic discount factor and $\widetilde{\lambda}_{t}$ is the saver's marginal utility of nominal income. Let's denote by $\frac{P_{j, t}(i)}{P_{j, t}}$ the relative price of variety $i$ in sector $j$. In a symmetric equilibrium in which $\frac{P_{j, t}(i)}{P_{j, t}}=1$ for all $i$ and $j$, and all firms employ the same amount of labor in each sector, the first order condition of the above problem reads:

$$
\begin{aligned}
\left(\left(1-\varepsilon_{j}\right)+\varepsilon_{j} m c_{j, t}\right) Y_{j, t}= & \vartheta_{j}\left(\pi_{j, t}-1\right) \pi_{j, t} \\
& -\vartheta_{j} E_{t}\left\{\frac{\Lambda_{t+1}}{\Lambda_{t}} \frac{P_{j, t+1}}{P_{j, t}}\left(\pi_{j, t+1}-1\right) \pi_{j, t+1}\right\} \quad(j=c, d)
\end{aligned}
$$

where $\pi_{j, t} \equiv \frac{P_{j, t}}{P_{j, t-1}}$ is the gross inflation rate in sector $j$ and

$$
m c_{j, t} \equiv \frac{W_{t}}{P_{j, t} A_{j, t}}
$$

is the real marginal cost in sector $j$. Recall that, due to labor being perfectly mobile, the nominal wage is common across sectors.

Rearranging equation (19) one can obtain the following sector-specific price setting constraint, assuming the form of a forward-looking Phillips curve 


$$
\begin{aligned}
\pi_{j, t}\left(\pi_{j, t}-1\right)= & \gamma E_{t}\left\{\frac{\Lambda_{t+1}}{\Lambda_{t}} \frac{P_{j, t+1}}{P_{j, t}} \pi_{j, t+1}\left(\pi_{j, t+1}-1\right)\right\} \\
& +\frac{\varepsilon_{j} A_{j, t} N_{j, t}}{\vartheta_{j}}\left(m c_{j, t}-\frac{\varepsilon_{j}-1}{\varepsilon_{j}}\right)
\end{aligned}
$$

for $j=c, d$, and where

$$
\begin{aligned}
& \frac{\Lambda_{t+1}}{\Lambda_{t}} \frac{P_{j, t+1}}{P_{j, t}}=\frac{U_{\widetilde{c}, t+1}}{U_{\widetilde{c}, t}} \quad(\text { if } \quad j=c) \\
& \frac{\Lambda_{t+1}}{\Lambda_{t}} \frac{P_{j, t+1}}{P_{j, t}}=\frac{U_{\widetilde{c}, t+1}}{U_{\widetilde{c}, t}} \frac{q_{t+1}}{q_{t}} \quad(\text { if } j=d)
\end{aligned}
$$

and

$$
\begin{gathered}
m c_{j, t}=\frac{-U_{n, t}}{U_{c, t} A_{c, t}} \quad(\text { if } j=c) \\
m c_{j, t}=\frac{-U_{n, t}}{U_{c, t} A_{d, t}} q_{t}^{-1} \quad(\text { if } j=d)
\end{gathered}
$$

Equation (21) constraints the evolution of sectoral prices when the price setting problem is inherently dynamic as in (18). It has the form of a so-called New Keynesian Phillips curve in that current inflation depends on future expected inflation and on the deviation of the real marginal cost from its flexible-price constant value. An equation such as (21) is a fundamental building block of the recent stream of models of the NNS. ${ }^{14}$

In the particular case of flexible prices the real marginal cost must be constant and equal to the inverse steady state markup $\frac{\varepsilon_{j}-1}{\varepsilon_{j}}$, for $j=c, d$. Notice that, in the durable sector, variations in the relative price of durables (possibly due to sectoral asymmetric shocks) drive a wedge between the marginal rate of substitution between consumption and leisure on the one hand and the marginal product of labor on the other. Hence the real marginal cost is directly affected by movements in the relative price. This aspect is important because it points to a typical inefficiency that constraints monetary policy in models with two sectors. Namely, in the presence of sectoral asymmetric disturbances, if

\footnotetext{
${ }^{14}$ See Gaòo and Gertler (1999), Woodford (2003).
} 
prices in either sector are sticky, simultaneous stabilization of real marginal costs in both sectors becomes unfeasible. In fact, asymmetric shocks will necessarily require equilibrium movements in the relative price.

\subsection{Market Clearing}

Equilibrium in the goods market of sector $j$ requires that the production of the final good be allocated to expenditure and to resource costs originating from the adjustment of prices

$$
\begin{gathered}
Y_{c, t}=C_{t}+\widetilde{C}_{t}+\frac{\vartheta_{c}}{2}\left(\pi_{c, t}-1\right)^{2} \\
Y_{d, t}=D_{t}-(1-\delta) D_{t-1}+\widetilde{D}_{t}-(1-\delta) \widetilde{D}_{t-1}+\frac{\vartheta_{d}}{2}\left(\pi_{d, t}-1\right)^{2}
\end{gathered}
$$

Equilibrium in the debt and labor market requires respectively:

$$
\begin{gathered}
B_{t}+\widetilde{B}_{t}=0 \\
\sum_{j} N_{j, t}=N_{t}
\end{gathered}
$$

\subsection{Equilibrium}

For any specified policy process $\left\{R_{t}\right\}$ and exogenous state vector $\left\{A_{c, t}, A_{d, t}\right\}$, an (imperfectly) competitive allocation is a sequence for $\left\{N_{t}, N_{c, t}, N_{d, t}, b_{t}, D_{t}, \widetilde{D}_{t}, C_{t}, \widetilde{C}_{t}, \pi_{c, t}, \pi_{d, t}, \psi_{t}, q_{t}\right\}$ satisfying (6) and (8) with equality, (9)-(12), (15), (16), (21), (24), (25), (27).

\section{Steady State of the Competitive Equilibrium}

In this section we analyze the features of the deterministic steady state associated to the competitive equilibrium. We emphasize two results. First, the borrower is always constrained in the steady state (and hence will remain such forever). This is assured by the assumption that the borrower is more impatient than the saver, hence the marginal 
utility of saving of the former is lower than the one of latter. Second, the steady state level of debt is unique and positive. It is a general result of models with heterogenous discount rates and borrowing constraints that the patient agent will end-up owning all available assets. This has been pointed out in earlier work by Becker (1980) and Becker and Foias (1987). In the context of our framework, this translates into the borrower holding a positive amount of debt in steady state.

We proceed as follows. In the steady state, the saver's discount rate pins down the real rate of return. Hence by combining the steady state version of (15), which implies $R=\frac{\pi_{c}}{\gamma}$, with (12), we obtain

$$
\psi=1-\frac{\beta}{\gamma}>0
$$

where $\pi_{c}$ is the steady state rate of inflation in non-durables. Notice that $\beta=\gamma$ implies $\psi=0$. In other words, absence of heterogeneity entails that the borrowing constraint does not bind. That would correspond to the standard scenario in a representative agent economy.

A corollary of $(28)$ is

$$
\frac{1}{\beta}>R R=\frac{1}{\gamma}
$$

where $R R$ is the steady state real interest rate. Hence, the borrower's discount rate exceeds the steady state real interest rate.

In a flexible price steady state for both sectors, taking the ratio of (22) and (23) the relative price of durables reads

$$
q=\frac{\frac{\varepsilon_{d}-1}{\varepsilon_{d}}}{\frac{\varepsilon_{c}-1}{\varepsilon_{c}}}
$$

Assuming equal price elasticity of demand in both sectors $\left(\varepsilon_{d}=\varepsilon_{c}\right)$, we have $q=1$. By evaluating (11) in the steady state (and given our preference specification) we obtain the relative consumption of durables by the borrower: 


$$
\frac{D}{C}=\frac{\alpha}{1-\alpha}[1-\beta(1-\delta)-(1-\chi) \psi]^{-\eta}
$$

Notice that the relative demand for durables is increasing in the shadow value of borrowing $\psi$. Intuitively, acquiring more durables allows to marginally relax the borrowing constraint.

The steady state leverage ratio, defined as the ratio between steady state debt and durable assets owned, can be written:

$$
\frac{b}{D}=(1-\chi)
$$

To pin down the level of debt we proceed as follows. We set parameter $v$ in order to set a given level of hours worked in the steady state ${ }^{15}(N=\bar{N})$. By combining (6), (8), (32) we can write:

$$
D=\frac{\bar{N}}{\mu^{c} \Phi}
$$

where $\mu^{c} \equiv \frac{\varepsilon^{c}}{\varepsilon^{c}-1}$ is the (steady state) markup in the non-durable sector and

$$
\Phi \equiv\left\{\frac{1-\alpha}{\alpha}[1-\beta(1-\delta)-\psi(1-\chi)]^{\eta}+\delta+\frac{(1-\gamma)(1-\chi)}{\gamma}\right\}
$$

Once obtained $D$ from (33), it is straightforward, using (32), to solve for the unique level of borrower's debt in the steady state. This steady state level of debt would be indeterminate in the special case in which agents did not exhibit heterogeneity in preference rates (see Becker (1980)).

\section{Optimal Monetary Policy}

Having laid out our framework, we next proceed to study the optimal conduct of monetary policy. The optimal monetary policy literature in the context of DSGE models with

\footnotetext{
${ }^{15}$ In particular, we will require that the borrower devotes to work one third of the time unit.
} 
nominal rigidities has soared in the last few years. ${ }^{16}$ However, these developments have neglected a number of features that are central to the present analysis: (i) the presence of nominal private debt and heterogeneity; (ii) the role of collateral constraints and (iii) the role of durable prices in affecting the ability of borrowing endogenously.

\subsubsection{The Ramsey Problem}

We assume that ex-ante commitment is feasible. In the classic approach to the study of optimal policy in dynamic economies (Ramsey (1927), Atkinson and Stiglitz (1980), Lucas and Stokey (1983), Chari, Christiano and Kehoe (1991)), and in a typical public finance spirit, a Ramsey planner maximizes household's welfare subject to a resource constraint, to the constraints describing the equilibrium in the private sector economy, and via an explicit consideration of all the distortions that characterize both the long-run and the cyclical behavior of the economy.

Recently there has been a resurgence of interest for a Ramsey-type approach in dynamic general equilibrium models with nominal rigidities. Khan et al. (2003) analyze optimal monetary policy in an economy where the relevant distortions are imperfect competition, staggered price setting and monetary transaction frictions. Schmitt-Grohe and Uribe (2004) and Siu (2004) focus on the joint optimal determination of monetary and fiscal policy. However, the issue of optimal policy in the face of households' credit constraints has been largely neglected.

A point of particular concern in defining the planner's problem in an economy with heterogeneity is the specification of the relevant objective function. Let's define by $\omega$ the weight assigned to saver's utility in the planner's objective function. Then we assume that the planner maximizes the following weighted utility functional:

$$
\mathcal{W}_{0} \equiv(1-\omega) \sum_{t=0}^{\infty} \beta^{t} U\left(C_{t}, D_{t}, N_{t}\right)+\omega \sum_{t=0}^{\infty} \gamma^{t} U\left(\widetilde{C}_{t}, \widetilde{D}_{t}\right)
$$

The Ramsey problem under commitment can be described as follows. Let $\left\{\lambda_{k, t}\right\}_{t=0}^{\infty}$

\footnotetext{
${ }^{16}$ To name a few, Adao et al. (2003), Khan et al. (2003), Schmitt-Grohe and Uribe (2005), Woodford (2003), King and Wolman (1999), Clarida et al. (1999), Benigno and Woodford (2005).
} 
$(k=1,2, .$.$) represent sequences of Lagrange multipliers on the constraints (6), (8), (9)-$ (12), (15), (16), (21), (24), (25), (27) respectively. For given stochastic processes $\left\{A_{c, t}\right.$, $\left.A_{c, t}\right\}_{t=0}^{\infty}$, plans for the control variables $\left\{N_{t}, N_{c, t}, N_{d, t}, b_{t}, D_{t}, \widetilde{D}_{t}, C_{t}, \widetilde{C}_{t}, \pi_{c, t}, \pi_{d, t}, \psi_{t}, q_{t}, R_{t}\right\}_{t=0}^{\infty}$, and for the costate variables $\left\{\lambda_{k, t}\right\}_{t=0}^{\infty}$ represent a first-best constrained allocation if they solve the following maximization problem:

$$
\max E_{0}\left\{\mathcal{W}_{0}\right\}
$$

subject to (6), (8), (9)-(12), (15), (16), (21), (24), (25), (27).

(Non-)Recursivity and Solution Approach As a result of (some of) the constraints in problem (35) exhibiting future expectations of control variables, the maximization problem as spelled out in (35) is intrinsically non-recursive. ${ }^{17}$ As first emphasized in Kydland and Prescott (1980), and then developed by Marcet and Marimon (1999), a formal way to rewrite the same problem in a recursive stationary form is to enlarge the planner's state space with additional (pseudo) costate variables. Such variables bear the crucial meaning of tracking, along the dynamics, the value to the planner of committing to the pre-announced policy plan. In Appendix $B$ and $C$ we show how to formulate the optimal plan in an equivalent recursive lagrangian form.

We then proceed in the following way. First, we compute the stationary allocations that characterize the deterministic steady state of the efficiency conditions of problem (35) for $t>0$. We label this as deterministic Ramsey steady state. We then compute a log-linear approximation of the respective policy functions in the neighborhood of the Ramsey steady state.

The spirit of this exercise deserves some further comments. In concentrating on the (log-linear) dynamics in the neighborhood of the Ramsey steady state we are in practice implicitly assuming that the economy has been evolving and policy been conducted around such a steady state for a long period of time. Technically speaking, this amounts to

\footnotetext{
${ }^{17}$ See Kydland and Prescott (1980). As such the system does not satisfy per se the principle of optimality, according to which the optimal decision at time $t$ is a time invariant function only of a small set of state variables.
} 
assuming that the initial values of the lagged multipliers involved in problem (35) are set equal to their initial steady state values. Khan et al. (2003) apply this strategy to an optimal monetary policy problem in a closed economy. Under certain conditions, one can show that this approach is equivalent to evaluating policy as invariant from a "timeless perspective", as described in Woodford (2003) and Benigno and Woodford (2005).

\subsection{Calibration}

In this section we describe our benchmark parameterization of the model. This will be useful for the quantitative analysis conducted below. We set the saver's and borrower's discount factors respectively to $\gamma=0.99$ and $\beta=0.98$. This implies an annual real interest rate (which is pinned down by the saver's degree of time preference) of $\left(\frac{1}{\gamma}\right)^{4}=1.04$.

Throughout we are going to assume that the Ramsey planner sets the preference weight $\omega=\frac{1}{2}$, although we will report sensitivity results on the value of this parameter.

We wish to work under the assumption that all outstanding debt is collateralized (hence we ignore the role of unsecured debt, e.g., credit cards) and that durables are longlived. Thus, in this context, durables mainly capture the role of housing. The depreciation rate for houses is much lower than the one usually assumed for physical capital, and is comprised between $1.5 \%$ and $3 \%$ per year. Since our model is parameterized on a quarterly basis, we set $\delta=0.025^{\wedge}(1 / 4)$.

The annual average loan-to-value (LTV) ratio on home mortgages is roughly 0.75 . This is the average value over the 1952-2005 period. This number has increased over time, as a consequence of financial liberalization, from about $72 \%$ at the beginning of the sample to a peak of $78 \%$ around the year 2000 . The same parameter is only slightly higher when considering mortgages on new houses. ${ }^{18}$ Hence we set the LTV ratio as $(1-\chi)=0.75$, which yields $\chi=0.25$.

The share of durable consumption in the aggregate spending index, defined by $\alpha$, is set in such a way that $\delta(D+\widetilde{D})$, the steady state share of durable spending in total spending, is 0.2 . This number is consistent with the combined share of durable consumption and

\footnotetext{
${ }^{18}$ The source for these numbers is the Federal Housing Finance Board, http://www.fhfb.gov.
} 
residential investment in the NIPA Tables. The elasticity of substitution between varieties in the non-durable sector $\varepsilon_{c}$ is set equal to 8 , which yields a steady state mark-up of about $15 \%$. As a benchmark case, we set the elasticity of substitution between durable and nondurable consumption $\eta=1$, implying a Cobb-Douglas specification of the consumption aggregator (3).

In order to parameterize the degree of price stickiness in non-durables, we observe that, by log-linearizing equation (21) around a zero-inflation steady state, we can obtain an elasticity of inflation to real marginal cost (normalized by the steady state level of output $)^{19}$ that takes the form $\frac{\varepsilon_{c}-1}{\vartheta}$. This allows a direct comparison with empirical studies on the New Keynesian Phillips curve such as Galí and Gertler (1999) and Sbordone (2002) using a Calvo-Yun approach. In those studies, the slope coefficient of the loglinear Phillips curve can be expressed as $\frac{(1-\widehat{\vartheta})(1-\beta \widehat{\vartheta})}{\widehat{\vartheta}}$, where $\widehat{\vartheta}$ is the probability of not resetting the price in any given period in the Calvo-Yun model. For any given values of $\varepsilon_{c}$, which entails a choice on the steady state level of the markup, we can thus build a mapping between the frequency of price adjustment in the Calvo-Yun model $\frac{1}{1-\vartheta}$ and the degree of price stickiness $\vartheta$ in the Rotemberg setup. Traditionally, the sticky price literature has been considering a frequency of four quarters as a realistic value. Recently, Bils and Klenow (2004) argue that the observed frequency of price adjustment in the U.S. is higher, and in the order of two quarters. As a benchmark, we parameterize $\frac{1}{1-\widehat{\vartheta}}=4$, which implies $\widehat{\vartheta}=0.75$. Given $\varepsilon_{c}=8$, the resulting stickiness parameter satisfies $\vartheta=\frac{Y \widehat{\vartheta}(\varepsilon-1)}{(1-\widehat{\vartheta})(1-\beta \widehat{\vartheta})} \sim 17.5$, where $Y$ is steady state output. In general, however, we will conduct sensitivity experiments on the role of non-durable price stickiness.

A critical issue concerns the assumed degree of price stickiness in durables. The comprehensive study by Bils and Klenow (2004) does not report any direct evidence on the degree of stickiness of long-lived durables, and housing in particular. It may appear reasonable to assume that house prices are in general more flexible than non-durable goods prices. Barski et al. (2005) argue that sales prices of new houses are flexible. One reason

\footnotetext{
${ }^{19}$ To produce a slope coefficient directly comparable to the empirical literature on the New Keynesian Phillips curve this elasticity needs to be normalized by the level of output when the price adjustment cost factor is not explicitly proportional to output, as assumed here.
} 
may be that, since the price of new houses can be negotiated, the role of fixed components such as menu costs can be more easily neutralized. In addition, Figure 2 shows that house prices feature a pronounced business cycle component.

To simplify matters we will then work under the extreme assumption that durable prices are flexible. This assumption is not immaterial. Barski et al. (2005) argue that the assumption of flexible durable prices dramatically affect the ability of standard sticky price models to reproduce the empirical effects of monetary policy shocks on durable and non-durable spending. In particular, if durable prices are flexible, and against the observed VAR-based evidence, durable spending contracts during expansions. In addition, and regardless of the assumed degree of stickiness in non-durables, flexible durable prices tend to impart a form of neutrality to policy shocks to the entire economy. However, in Monacelli (2005) we argue that the introduction of borrowing constraints and the consideration of durables as collateral assets help in reconciling the model with the observed empirical evidence. In this vein, borrowing constraints act as a substitute of nominal rigidity in durable prices. In an extreme case, when also non-durable prices are assumed to be flexible, borrowing constraints can even partially act as a substitute of nominal rigidity altogether in generating non-neutral effects of monetary policy.

Table 1 summarizes the details of our baseline calibration:

\begin{tabular}{|c|c|c|}
\hline \multicolumn{3}{|c|}{ Table 1. Baseline Calibration } \\
\hline \hline Parameter & Description & Value \\
\hline \hline$\beta$ & borrower's discount rate & 0.98 \\
\hline$\gamma$ & saver's discount rate & 0.99 \\
\hline$\delta$ & durable depreciation rate & $0.025^{\frac{1}{4}}$ \\
\hline$\chi$ & inverse LTV ratio & 0.25 \\
\hline$\omega$ & Ramsey preference weight & 0.5 \\
\hline$\vartheta_{d}$ & price stickiness in D sector & 0 \\
\hline$\vartheta_{c}$ & price stickiness in ND sector & 17.5 \\
\hline$\varepsilon_{c}$ & price elasticity of demand in D sector & 8 \\
\hline$\varepsilon_{d}$ & price elasticity of demand in ND sector & 8 \\
\hline$\eta$ & elasticity of substitution btw. D and ND & 1 \\
\hline
\end{tabular}




\section{The Role of Nominal Debt}

We begin our analysis by focussing on the role of durable goods and nominal private debt in shaping the optimal policy problem. To that goal, we first analyze the optimal policy problem in a simplified version of our model featuring no borrowing constraints. Here we wish to understand whether the mere introduction of durable consumption can alter the basic prescription of price stability of the baseline New Keynesian sticky price model. We conclude that durability per se is not sufficient to alter that prescription. We then proceed by introducing household heterogeneity and a role for private debt. We show that the presence of nominal debt generates a redistributive margin for monetary policy which induces the policy authority to optimally generate deviations from price stability. In equilibrium, though, we find that those deviations are small.

In both cases, we work with a simpler goods market structure, featuring only one final good sector. In particular, the competitive final good producer assembles intermediate goods purchased from a continuum of monopolistic competitive producers who run a linear production function as in (17) and set prices optimally subject to quadratic adjustment costs. In this simpler economy, the final good can be costlessly transformed into both non-durable and durable consumption. Hence the relative price between durable and nondurable goods is always $q_{t}=1$. As a result, movements in the relative price of durables do not affect the ability of borrowing directly.

The reason for first concentrating on this simpler case is twofold. First, it allows us to study the role of nominal debt per se in shaping the normative conclusions of a standard New Keynesian model. Second, it allows to abstract from an additional distortion inherent to the two-sector economy and stemming from fluctuations in the relative price of durables. In fact, with two sectors, asymmetric sectoral shocks necessarily require, as already illustrated above, an adjustment in relative prices that cannot be brought about efficiently if prices are sticky in one or both sectors. ${ }^{20}$

\footnotetext{
${ }^{20}$ See Aoki (2003) and Woodford (2003) for an analysis of optimal monetary policy in the face of sectoral asymmetric shocks.
} 


\subsection{Benchmark: Price Stability with Durable Goods and Free Borrowing}

In order to understand the role of durable goods in the monetary policy problem, we begin by assuming that agents can borrow and lend freely at the market interest rate. This amounts to assuming away heterogeneity in patience rates. To obtain such benchmark version of our model it suffices to evaluate the system of first order conditions (9)-(12) in the particular case of $\psi_{t}=0$. This version of the model corresponds to a standard representative agent sticky price model simply augmented by the introduction of durable goods. In Appendix $A$ we describe the structure of the competitive equilibrium in this case and the corresponding simplified form of the optimal policy problem.

Figure 4 displays impulse responses to a productivity shock in the benchmark economy with sticky prices, durable goods and free borrowing under the Ramsey equilibrium.

We compare two cases: (i) $\delta=1$ (full depreciation), which amounts to assuming away durability; and (ii) $\delta=0.025^{\frac{1}{4}}$, which is the value for the physical depreciation rate assumed in our baseline parameterization. It is evident that the benchmark result of price stability under the Ramsey policy is robust to the introduction of durable goods. With higher productivity (and income), the household would like to increase both durable and non-durable spending. Since durables can only be accumulated slowly (recall that the household wishes to smooth the end-of-period stock $D_{t}$ and not the flow of durable spending), and since efficiency requires to equate the marginal utility of current consumption to the expected discounted marginal value of acquiring a new durable, non-durable consumption also moves more gradually, relative to the case $\delta=1$. Inflation, however, is completely stabilized in both cases. The intuition is simple. The presence of durables does not introduce per se any additional distortion that the planner wishes to neutralize. Hence, as it is well understood in the standard case, the planner induces the economy to behave as if prices were completely flexible. This is obtained via monetary policy generating an expansion in demand, which induces firms to smooth markup fluctuations completely, thereby validating unchanged prices (zero inflation) as an equilibrium out- 

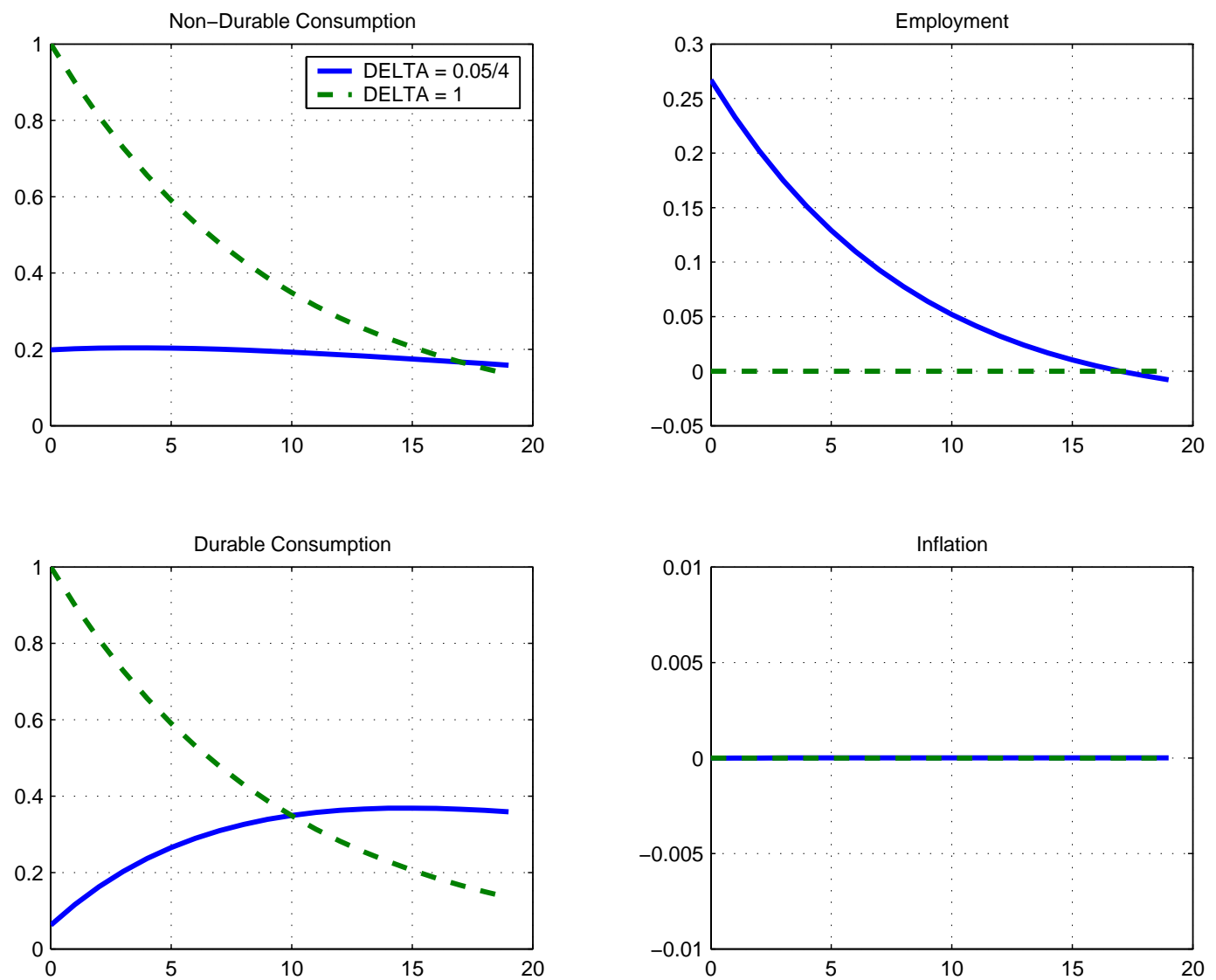

Figure 4: Responses to a Productivity Shock under the Ramsey Equilibrium in the Model with no borrowing constraints: with durability (solid line) and without durability $(\delta=1$, dashed line). 
come. $^{21}$

\subsection{Optimal Inflation Volatility with Nominal Debt}

Next we wish to consider the role of nominal private debt. In this version of the model, we re-introduce two critical features: (i) heterogeneity (in patience rates); (ii) a collateral constraint (on the impatient household). Still, we continue to work under the one final good sector model (whose details are reported in Appendix B). In this context, we wish to understand whether the possibility of using inflation to affect borrower's net worth, and therefore to marginally redistribute wealth from the saver to the borrower, may induce the planner to deviate from a strict price stability policy.

Figure 5 illustrates how the introduction of borrowing constraints affects the equilibrium dynamics. Once again, we show impulse responses to a rise in productivity. We compare two alternative cases, corresponding to two values of parameter $\chi$ (solid line for low $\chi$ and dashed line for high $\chi$ ). A higher value of $\chi$ implies a lower LTV ratio and therefore a reduced ability to collateralize the purchase of durables (hence, broadly speaking, a tighter borrowing constraint). Unlike a standard permanent-income consumer, the borrower has preferences tilted towards current consumption. Hence, in the face of higher productivity (income), the borrower wishes to increase current consumption (reduce saving) and do so to a larger extent than the saver. In equilibrium, the two agents find it optimal to trade debt, with the saver ending up lending resources to the borrower, thereby financing the surge in consumption of the latter.

Notice that the presence of a collateral requirement (whose strength is indexed by $\chi$ ) induces a wealth effect on borrower's labor supply. In order to expand consumption, the borrower needs to optimally balance the purchasing of new debt with an increase in labor supply necessary to finance new collateral. The tighter the borrowing constraint (i.e., the

\footnotetext{
${ }^{21}$ The implication of durability in response to productivity shocks are relevant for another dimension, namely the equilibrium response of employment. One can show that whereas employment tends typically to fall in sticky price models in response to a rise in productivity (as a result of a downward shift in labor demand, see Galí (1999)), the introduction of durables reverses the sign of that response (see Monacelli (2006) on this particular point). This is also evident in Figure 4.
} 

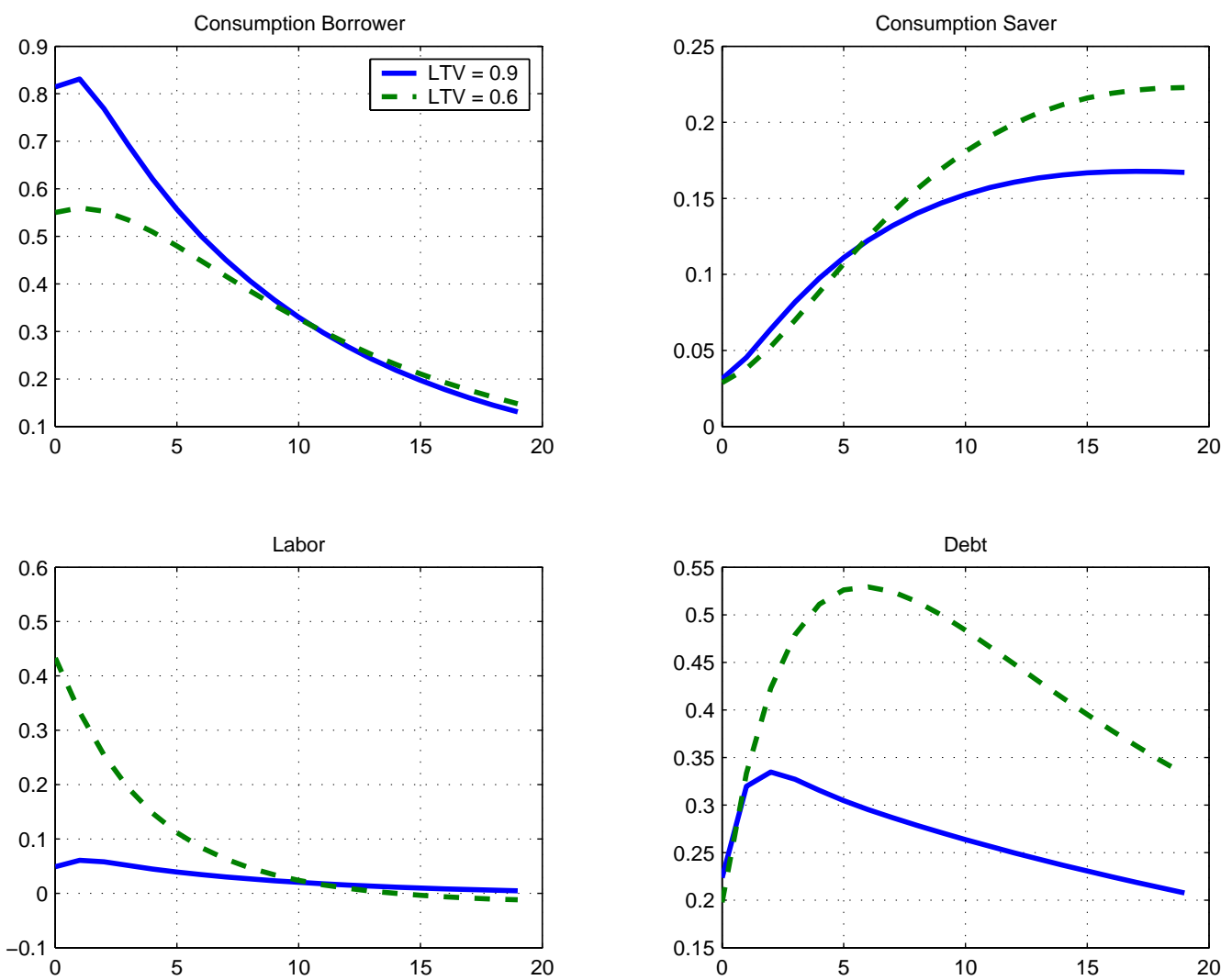

Figure 5: Productivity Shock under the Ramsey Equilibrium: Model with Borrowing Constraint (low vs. high Loan-To-Value Ratio $1-\chi$ ). 


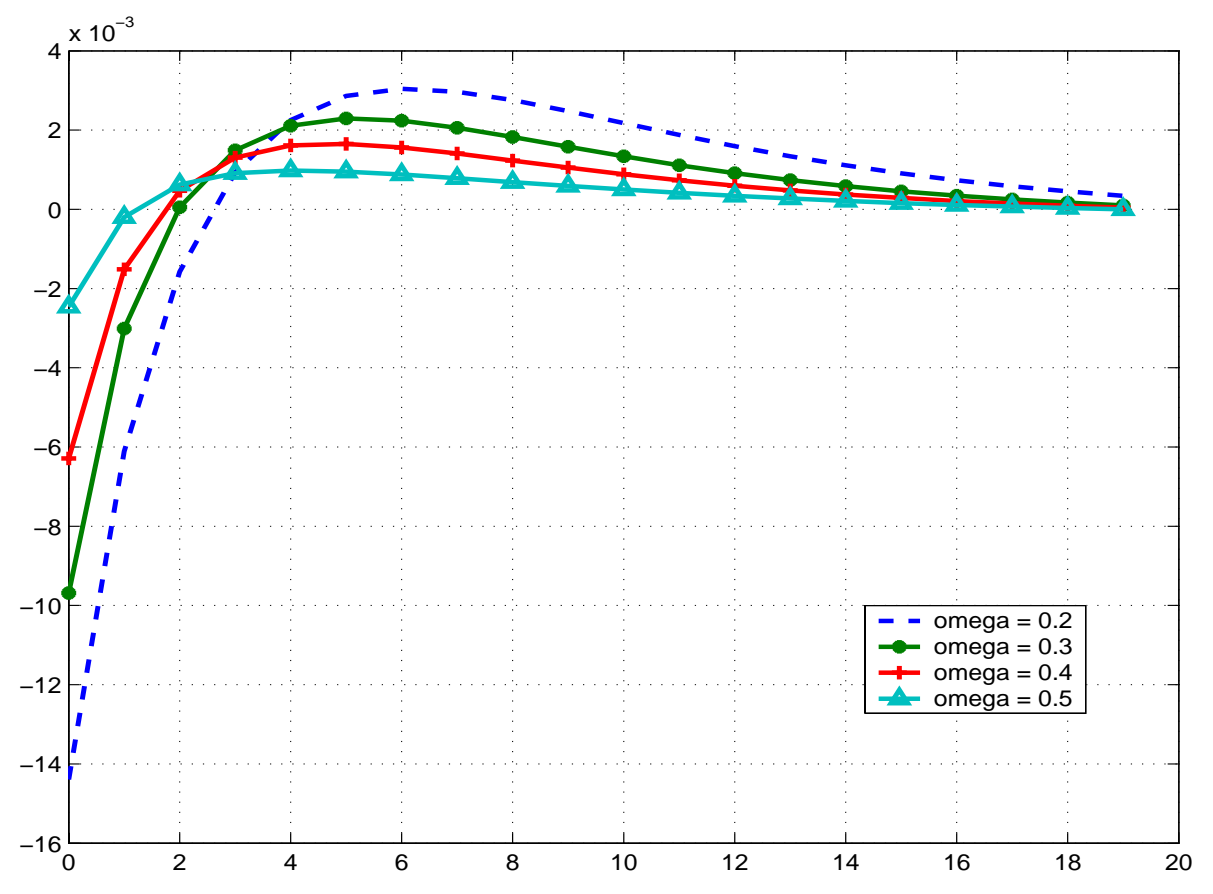

Figure 6: Optimal Response of Inflation to a Productivity Shock: Effect of Varying Saver's Weight $\omega$ in Planner's Objective.

higher $\chi$ ), the more stringent the necessity of increasing labor supply. This debt-labor supply margin is indeed a general feature of models with collateral requirements. ${ }^{22}$

In principle, since debt is predetermined in nominal terms, monetary policy can affect borrower's net worth by altering the real value of the outstanding debt service. Hence it is interesting to understand whether movements in inflation are part of the Ramsey equilibrium. In Figure 6 we show impulse responses of inflation to the same productivity shock. We report paths for inflation under alternative values of $\omega$, the weight attributed to saver's utility in the Ramsey optimization problem. It is clear that the introduction of nominal debt alters the conclusions of the benchmark model, in that it constitutes a motivation for deviating from a price stability prescription.

\footnotetext{
${ }^{22}$ For instance, Campbell and Hercowitz (2005) emphasize this channel as a vehicle for business cycle expansions/contractions. In their analysis, the reduction in equity requirements brought about by the financial reforms of the early eighties is a candidate theory of the so-called "great moderation" (Stock and Watson (2002)).
} 


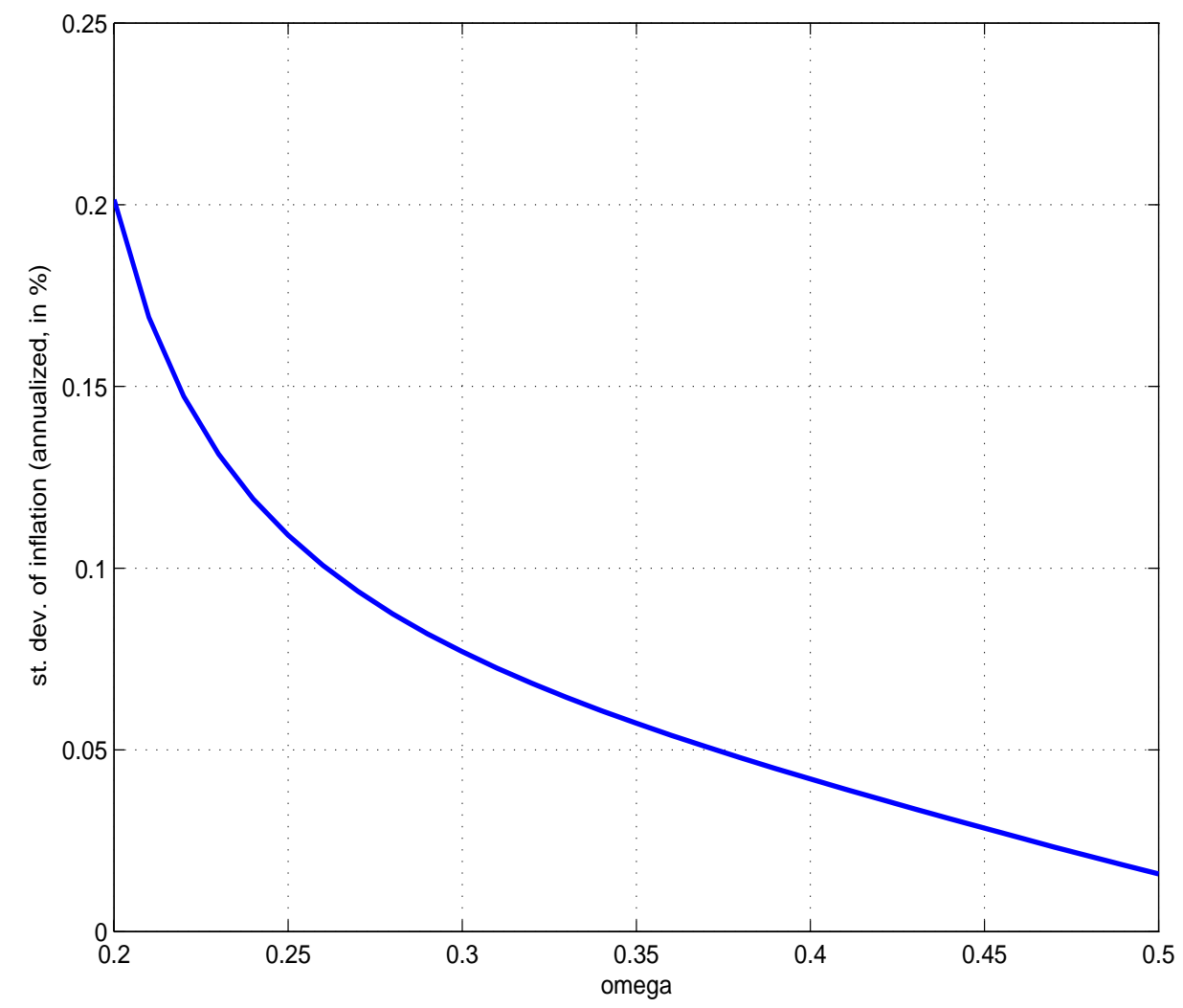

Figure 7: Optimal Inflation Volatility: Effect of Varying Saver's Weight $\omega$ in Planner's Objective Function.

\subsection{Heterogeneity}

Notice that the amplitude of the inflation movements is decreasing in the saver's weight $\omega$. Intuitively, the larger the Ramsey weight on saver's utility, the smaller the inflation redistributive motive and, supposedly, the smaller the variability in inflation. This conjecture is confirmed in Figure 7, which plots the volatility of inflation as a function of $\omega$. Under the Ramsey equilibrium, larger values of $\omega$ correspond to a smaller volatility of inflation.

Analyzing the effects of alternative values of $\omega$ is one way to address the role of heterogeneity. Another way is to look at the effect on inflation variability of different values of the borrower's patience rate $\beta$. For values of $\beta$ approaching $\gamma$, we should 


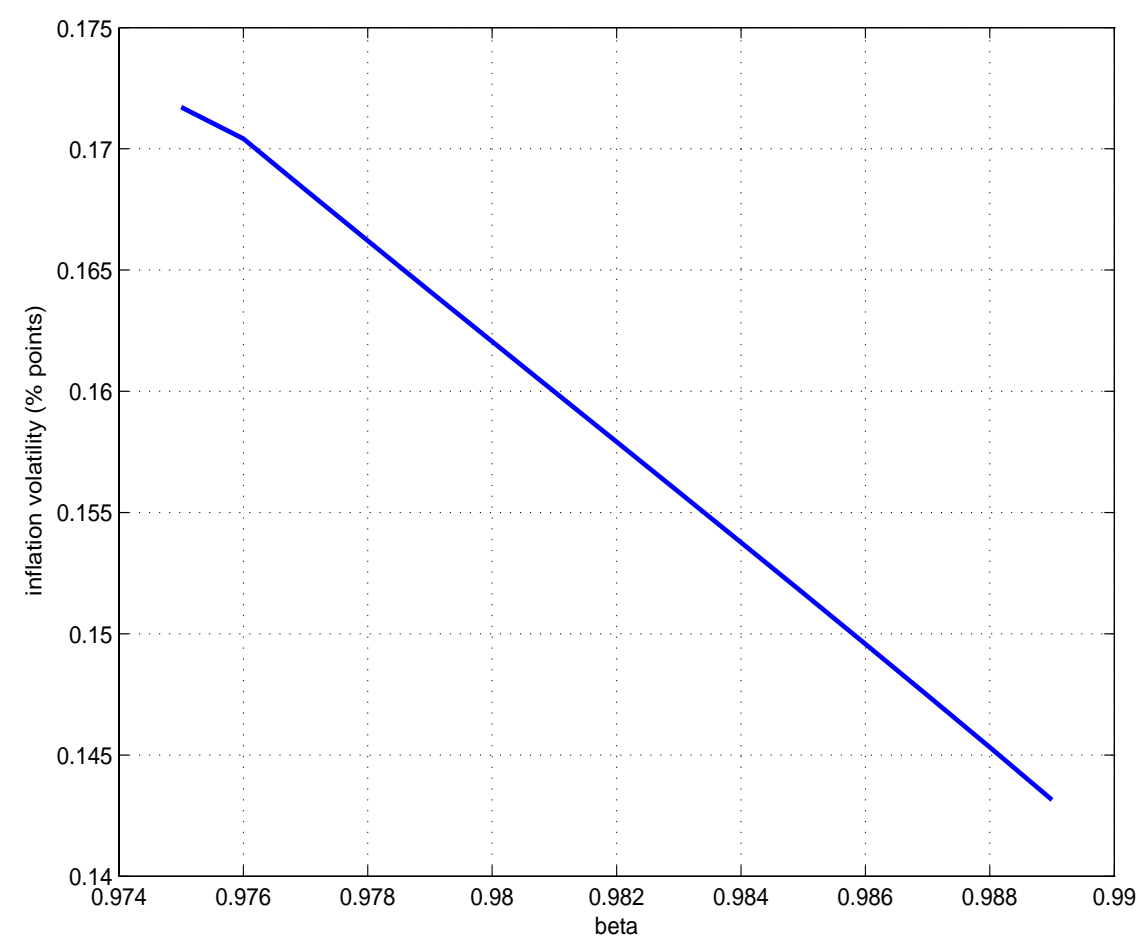

Figure 8: Optimal Inflation Volatility: Effect of Varying Patience Rate $\beta$.

observe a vanishing of the role of heterogeneous patience rates which is key in driving the consumption-saving preferences of the two agents over the business cycle. Figure 8 plots optimal inflation volatility as a function of $\beta$.

The support of $\beta$ is limited to the right by $\gamma$, which corresponds to the saver's patience rate. Thus we see that inflation variability falls for larger values of $\beta$. In particular, as the borrower's patience rate converges to the one of the saver, inflation volatility approaches the benchmark value of zero. In other words, when heterogeneity in patience rates vanishes, the borrowing constraint ceases to be binding (in and in the vicinity of the steady state), and the Ramsey equilibrium tends to mimic the optimal dynamics of a representative agent economy with price stickiness represented in the previous section. In that environment we have already shown that reproducing the flexible price allocation corresponds to the constrained optimum. 


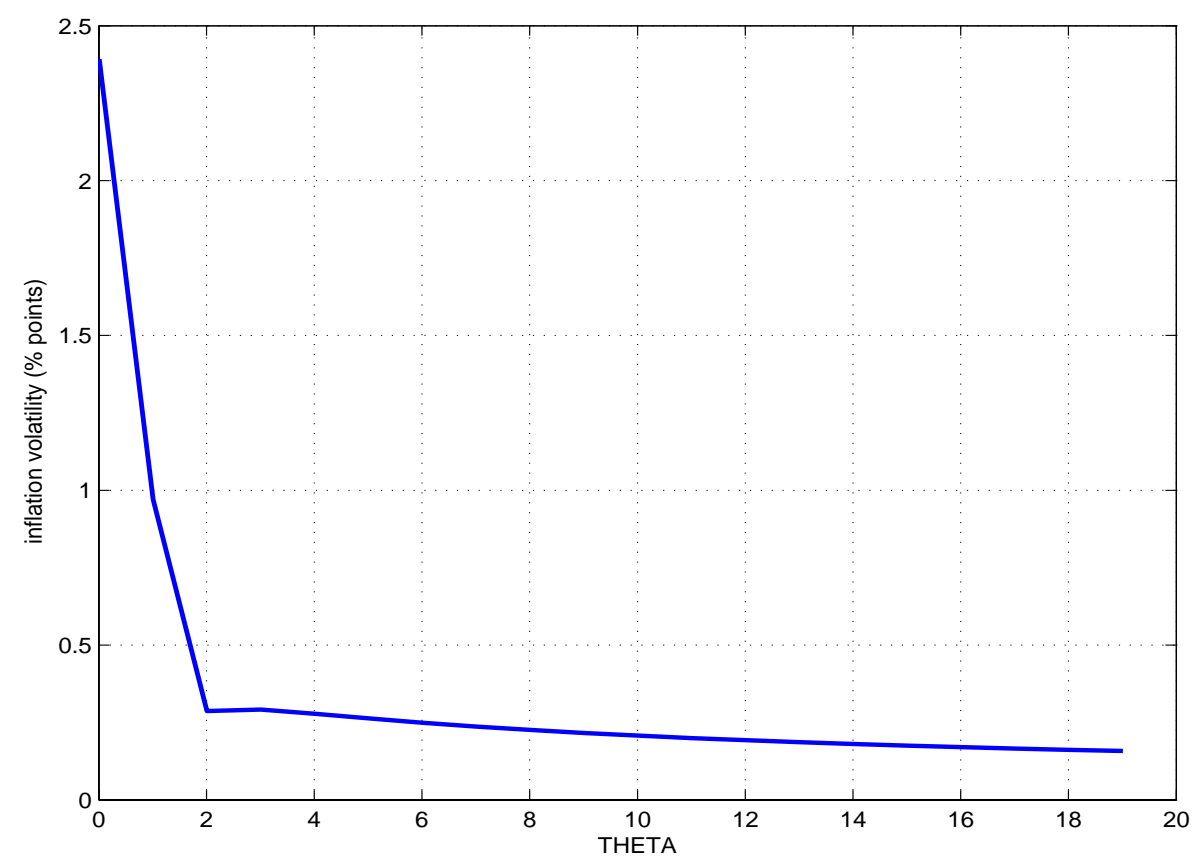

Figure 9: Optimal Inflation Volatility: Effect of Varying Price Stickiness $\vartheta$.

\subsection{Price Rigidity}

It is important to emphasize that movements in inflation in the Ramsey equilibrium are overall very small. Due to the presence of price stickiness, in fact, inflation is costly. Hence monetary policy has to optimally balance the incentive to offset the price stickiness distortion with the one of marginally relaxing borrower's collateral constraint via the redistributive effect of inflation. To explore how this tradeoff is resolved, in Figure 9 we plot the volatility of inflation in the Ramsey equilibrium against the degree of nominal price stickiness $\vartheta$. The extreme case of $\vartheta$ approaching zero corresponds to full price flexibility. Hence we see that changes in the the price stickiness parameter have a dramatic effect on the equilibrium volatility of inflation. In the case of flexible prices, inflation volatility (on an annualized basis) is around $2.5 \%$. Yet already for small values of $\vartheta$, the volatility of inflation drops significantly and remains barely positive.

This result points to a general feature shared with a large array of equilibrium busi- 
ness cycle models recently employed for optimal monetary policy analysis: namely, the important quantitative role played by the price stickiness distortion in driving the optimal monetary policy prescription towards stable inflation. One may notice the resemblance of this result (despite the very different environment) with the one of Schmitt-Grohe and Uribe (2003) and Siu (2003), who analyze a joint problem of optimal monetary and fiscal policy. In that case, and in the presence of nominal non-state contingent government debt, the planner balances the incentive to generate inflation variability, in order to reduce the finance cost of debt, with the cost of price variability due to price stickiness. Like here, optimal monetary policy points to resolving the tradeoff in favor of minimizing the price stickiness distortion.

\section{Durable Prices and Collateral}

So far we have worked with a specialized version of our model featuring only one final good sector. In so doing, we have neglected any role for endogenous fluctuations in the relative price of durables in directly affecting the ability of borrowing. Our normative analysis has so far highlighted the role of two distortions. On the one hand, the planner tries to minimize the cost of price variability due to the presence of price adjustment costs. At the same time, with nominal debt, the presence of a collateral requirement induces the planner to resort to inflation variability in order to marginally affect the borrowing constraint. However, the specification of a two sector model introduces further distortions. With sectoral asymmetric shocks, the equilibrium dynamics require an adjustment in the relative price of durables. In the presence of price frictions and/or borrowing constraints, these relative price movements may be brought about in a way non consistent with efficiency. We investigate this point below.

\subsection{Inefficient Movements in Relative Prices}

Let us define the natural relative price of durables as the relative price prevailing with full price flexibility and free borrowing. In addition, we can define the relative price gap 
as the deviations of the relative price from that natural benchmark.

Figure 10 illustrates how the introduction of price stickiness and/or borrowing constraints alters the equilibrium dynamics. We plot selected variables in response to a rise in productivity in the non-durable sector for three alternative cases: (i) the solid lines report responses in the natural case, i.e., an economy with fully flexible prices and free borrowing; (ii) the dashed lines display the equilibrium in the presence of collateral requirements only (therefore with full price flexibility in both sectors); (iii) the dotted lines display the dynamics when the two-sector model with borrowing constraints is augmented with price stickiness in non-durables.

Consider the behavior in the natural case, which constitutes our benchmark. In the absence of borrowing frictions and with price flexibility in both sectors, the rise in productivity in non-durables is completely absorbed via a rise in the relative price of durables and an expenditure switching towards non-durables. Consistently, equilibrium demand for durables is unchanged, and a rise in consumption is observed only in the non-durable sector.

Matters are different when a borrowing constraint is added (although still under the assumption of full price flexibility in both sectors). In this case (dashed line) the demand for durables must rise due to the need of financing further borrowing, with this expansion in durable demand being amplified for larger values of the inverse loan-to-value parameter $\chi$. Importantly, in an efficient equilibrium with free borrowing and lending, the borrower would indeed like (given his impatience) to expand borrowing to finance current consumption, but in that case there would be no need to resort to an increase in demand for durables. Hence we observe that the relative price of durables rises above its natural level in the presence of collateral constraints, with this effect being driven by a collateral motive on durable demand.

Figure 10 also illustrates that the adding of stickiness in non-durable prices introduces a further source of deviation from the natural relative price. With sticky non-durable prices, the demand for debt rises more and so does the demand for durables, inducing a larger increase in the relative price gap. Overall the results indicate that both frictions 

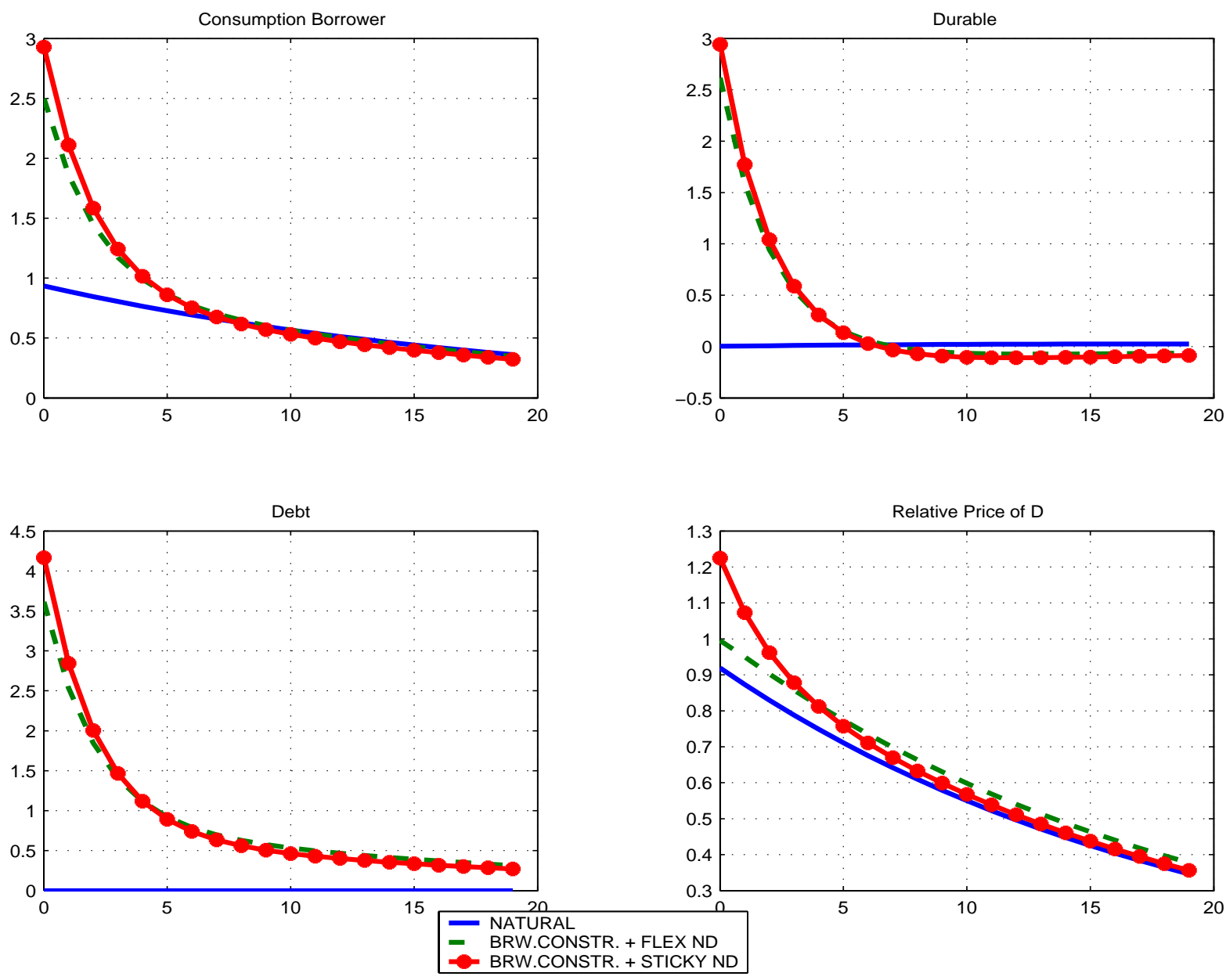

Figure 10: Responses to a Productivity Shock in the Two-Sector Model: (i) Natural vs. (ii) Borrowing Constraints with Flexible Non-Durable Prices vs. (iii) Borrowing Constraints with Sticky Non-Durable Prices. In these simulations monetary policy is described by a simple Taylor rule $R_{t}=1.5 \pi_{c, t}$. 
contribute to generate inefficient movements in the relative price $q_{t}$ from its natural level.

\subsection{Collateral Effects}

In the two-sector model, movements in the relative price of durables are important for they exert an endogenous effect on the ability of borrowing. In this section we highlight the importance of this transmission channel linking durable (asset) price variations to consumption. We define as collateral effect the acceleration on borrowing and consumption that derives from the price of durables directly affecting the right hand side of equation (8). The intuition is akin to the "credit-cycle" phenomenon emphasized in Kiyotaki and Moore (1997) and Iacoviello (2005). The mechanism is simple. The rise in productivity in the non-durable sector boosts the relative price of durables and therefore the value of the asset that can be used as a collateral (the term $q_{t} D_{t}$ in equation (8)). The resulting increase in borrower's net worth rises the demand for borrowing which is necessary to finance a surge in consumption. In turn, the higher demand for collateral boosts durable prices even further, feeding back on the value of available collateral in a self-sustained cycle.

To illustrate this effect on borrowing and consumption, we compare responses to a productivity shock (in the non-durable sector) in two cases: with and without collateral effect. The absence of a collateral effect is obtained by specifying the borrowing constraint in the slightly modified form:

$$
b_{t}=(1-\chi) D_{t} q_{t}^{\xi}
$$

where $\xi \in[0,1]$. We can broadly define $\xi$ as a parameter measuring the ability of the constrained household to convert a rise in his net worth in ability of borrowing. The case with full collateral effect corresponds to $\xi=1$, while the case without collateral effect corresponds to $\xi$ small and close to zero. Figure 11 suggests that movements in durable prices are crucial for the amplification of the joint dynamics of borrowing and consumption. With a collateral effect at work, the rise in durable consumption and debt is much larger relative to the case in which the collateral effect is artificially shut down. 

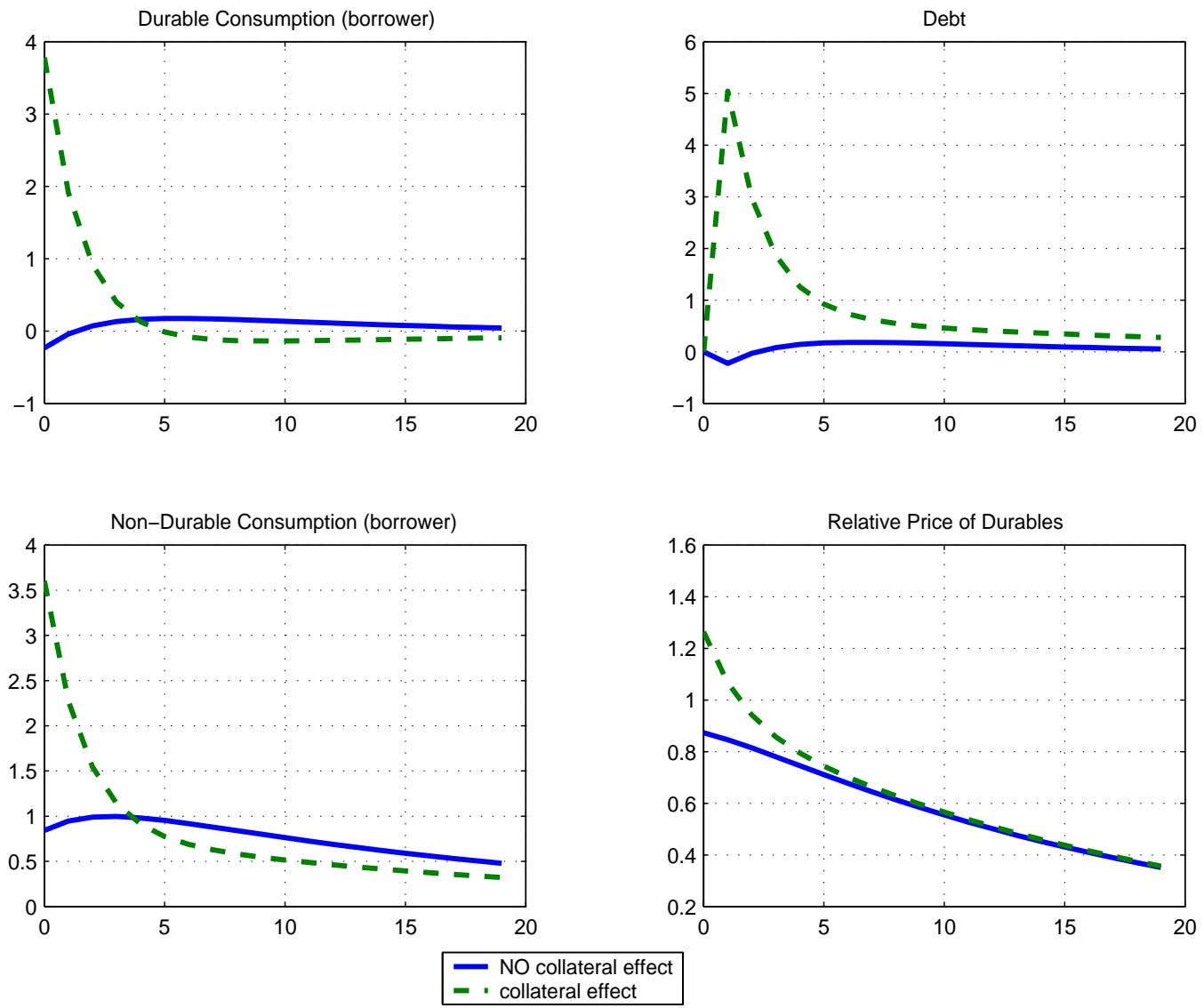

Figure 11: Durable Prices and The Role of Collateral Effect on Borrowing (Responses to a Productivity Shock in ND Sector). In these simulations monetary policy is described by a simple Taylor rule $R_{t}=1.5 \pi_{c, t}$. 
Importantly, the collateral effect produces also an acceleration in borrower's nondurable consumption. The intuition works as follows. The rise in the real price of durables, via its direct effect on the collateral value, induces a fall in the marginal value of borrowing ( $\psi_{t}$ in our model). In other words, the rise in asset prices boosts the ability of borrowing and induces a marginal relaxation of the borrowing constraint. This implies, for the borrower, a fall in the marginal utility of current (non-durable) consumption relative to the option of shifting consumption intertemporally (in other words, a violation of the Euler equation, see equation (12)), which can be validated only by a rise in current consumption. In turn, the increased demand for borrowing further boosts durable demand and in turn the real price of durables, inducing a circle that positively feedbacks on non-durable consumption.

\subsection{Durable Prices: Ramsey vs Taylor}

In this section we investigate the behavior of the relative price of durables in the Ramsey equilibrium. To that goal we proceed by solving the more general version of the Ramsey problem, as outlined in (35). In particular, we wish to understand whether dampening the volatility of durable (asset) prices should be of any concern for monetary policy in this context. It is important to recall, as suggested above, that two are the reasons for why the relative price of durables fluctuates in deviation from its natural benchmark: (i) the presence of a collateral requirement; (ii) price stickiness in the non-durable sector.

To this goal, we compare the dynamics in the Ramsey equilibrium with a simple generalized Taylor type rule of the following form:

$$
\frac{R_{t}}{R}=\left(\frac{\pi_{c, t}}{\pi_{c}}\right)^{\phi_{\pi}}\left(\frac{q_{t}}{q}\right)^{\phi_{q}} \quad \phi_{\pi}>1, \phi_{q} \geq 0
$$

where $R, \pi_{c}, q$ correspond, respectively, to the steady state values of $R_{t}, \pi_{c, t}, q_{t}$. A rule such as (37) encompasses several alternative policy regimes, including the extreme cases of: (i) strict non-durable inflation targeting $\left(\phi_{\pi} \rightarrow \infty\right.$, henceforth $N D$-targeting), and (ii) strict durable price targeting $\left(\phi_{q} \rightarrow \infty\right.$, henceforth $q$-targeting $)$. 
In Figure 12 we compare the effects of a productivity in the non-durable sector under the Ramsey equilibrium with the extreme cases of ND targeting and q-targeting. One central finding is immediately worth noticing: the amplitude of the response of the relative price of durables in the Ramsey equilibrium is intermediate between the extreme cases of ND targeting and q-targeting. In general, this feature of the Ramsey allocation is common to the equilibrium behavior of the entire set of variables displayed.

Consider a strict q-targeting rule first, and compare it with the outcome under the Ramsey equilibrium. Evidently, this type of policy rule is largely detrimental for the borrower. Not only it does induce a shut-off of the collateral effect on borrowing outlined above, but it hinders the necessary relative sectoral adjustment, thereby generating a sizeable drop in the demand for collateral and borrowing, and therefore, in turn, for nondurable consumption by the borrower. At the same time, since debt falls in equilibrium, this reduces the consumption-smoothing possibilities by the saver, whose consumption volatility is in fact amplified relative to the Ramsey-optimal allocation.

Consider next a ND-targeting rule. In that case, the effect is somewhat symmetric. Relative to a Ramsey equilibrium, strict stabilization of non-durable inflation induces an acceleration in the relative price of durables and in turn an amplified rise in borrowing and durable demand. This, in turn, is also reflected in an amplified surge in consumption by the borrower.

Interestingly, the Ramsey-optimal policy emerges as an intermediate case between the two extreme targeting cases outlined above. ${ }^{23}$ In fact, the planner wishes to optimally balance two margins. On the one hand, the incentive to partially stabilize inefficient movements in the relative price of durables due to the presence of a collateral constraint. On the other hand, the planner has also the objective to stabilize non-durable inflation due to the presence of a sticky price distortion in that sector. Hence a monetary policy that aimed at strictly targeting non-durable inflation would lead to an excess volatility in

\footnotetext{
${ }^{23}$ Notice that the behavior of the relative price of durables $q_{t}$ is exactly symmetric in the case of a productivity shock in the durable sector. In that case (not displayed here), $q_{t}$ tends to fall under ND-targeting, while it falls less in the Ramsey equilibrium.
} 

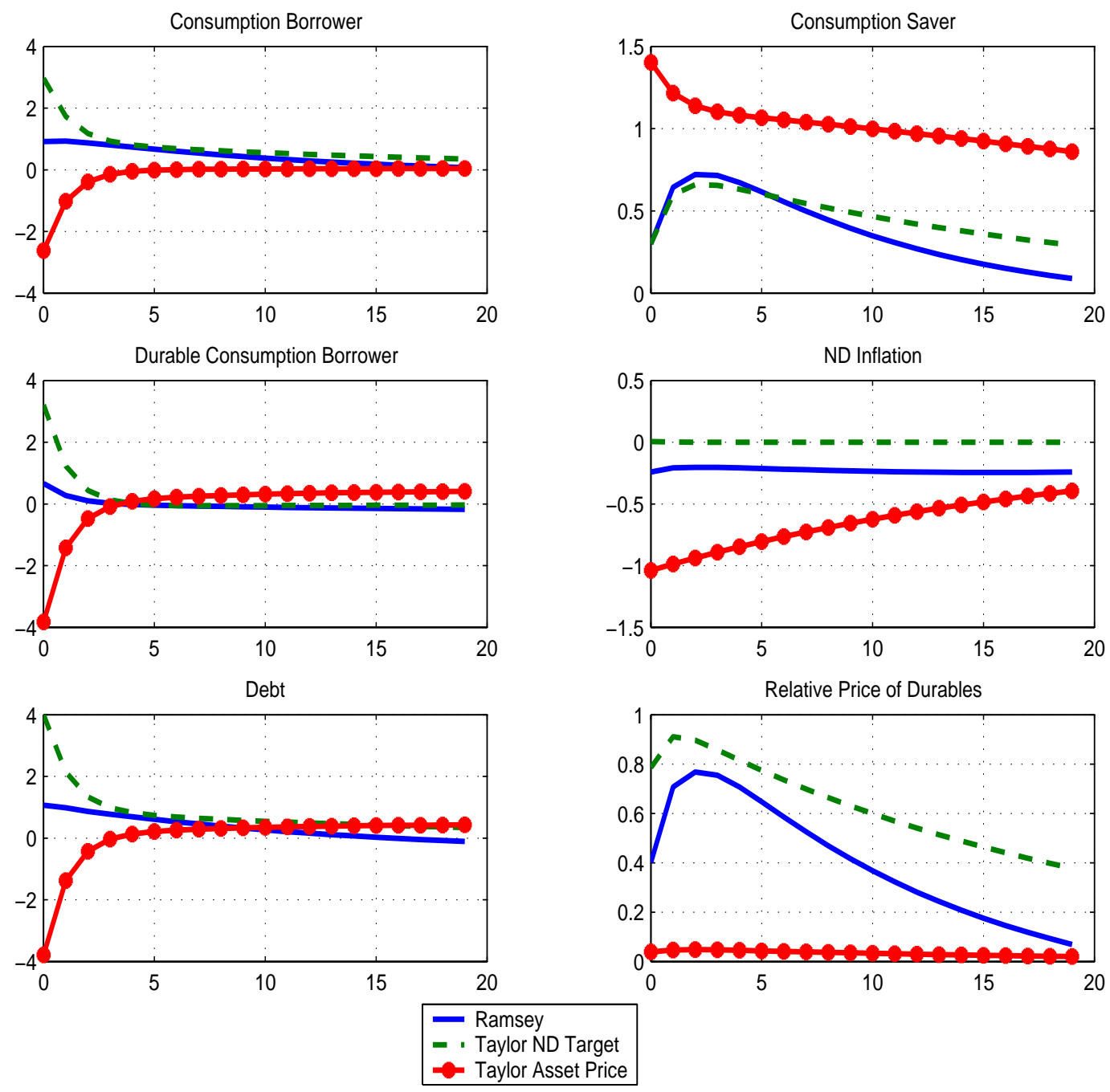

Figure 12: Ramsey vs. Strict ND-targeting vs. Strict q-targeting: Responses to a Productivity Shock in ND Sector. 
real durable prices and to an excess volatility in borrower's consumption and debt.

\section{Conclusions}

We have laid out a framework for the analysis of optimal monetary in the presence of nominal private debt and of a collateral constraint on borrowing. The emergence of a borrowing-lending decision in the equilibrium of our economy requires heterogeneity between a patient and an impatient agent. At the margin, and relative to a standard representative agent economy with price stickiness, optimal policy in this context requires a partial use of inflation volatility with a redistributive motive. However, the fact that, due to the presence of price stickiness, inflation movements are costly, heavily biases the optimal policy prescription towards low inflation volatility. When durable prices have the additional effect of altering the value of the collateral and in turn the ability of borrowing, optimal policy has a motive for partially stabilizing the relative price of durables. This is due to the fact that the model incorporates a motive for durable goods demand (and therefore a pressure on prices) which is strictly linked to the presence of an inefficient collateral requirement.

There are several other features that have remained unexplored in the current context and that would deserve a more thorough normative analysis. First, detailed institutional characteristics of mortgage markets should be more adequately incorporated. For instance, the presence of an equity withdrawal margin, the possibility of resorting to mortgage refinancing, as well as the decision of opting for a flexible vs. fixed rate mortgage structure. Second, the analysis should contemplate the possibility that borrowing constraints may be only occasionally binding, and that, in the presence of uncertainty, the borrower's decisions may be driven by a precautionary saving motive. Third, one may wish to extend this framework to the presence of collateral requirements on other forms of spending, such as business investment. Fourth, one may think of extending the present context to comprise the interaction between monetary and fiscal policy. The analysis of the latter, in particular, may fruitfully take advantage of the implications of the assumed 
heterogeneity and of the presence of a collateral constraint, in order to emphasize, in particular, transmission channels of fiscal policy alternative to the typical ones embedded in the standard neoclassical growth model. 


\section{A Competitive Equilibrium with Durable Goods and Free Borrowing}

The (symmetric) equilibrium in the one-sector economy with free borrowing, durable goods and sticky prices can be described (in compact form) by the following set of equations:

- efficiency condition on non-durable and durable consumption

$$
1=\frac{U_{d, t}}{U_{c, t}}+\beta(1-\delta) E_{t}\left\{\frac{U_{c, t+1}}{U_{c, t}}\right\}
$$

- standard Euler equation

$$
1=\beta E_{t}\left\{\frac{U_{c, t+1}}{U_{c, t}} \frac{R_{t}}{\pi_{t+1}}\right\}
$$

- Phillips curve

$$
\left(\pi_{t}-1\right) \pi_{t}=\gamma E_{t}\left\{\frac{U_{c, t+1}}{U_{c, t}}\left(\pi_{t+1}-1\right) \pi_{t+1}\right\}+A_{t} N_{t} \frac{\varepsilon}{\vartheta}\left(-\frac{U_{n, t}}{A_{t} U_{c, t}}-\frac{\varepsilon-1}{\varepsilon}\right)
$$

- resource constraint

$$
A_{t} N_{t}=C_{t}+D_{t}-(1-\delta) D_{t-1}+\frac{\vartheta}{2}\left(\pi_{t}-1\right)^{2}
$$

where $\pi_{t}$ is CPI (final goods) inflation. For any policy sequence $\left\{R_{t}\right\}_{t=0}^{\infty}$ and stochastic process $\left\{A_{t}\right\}_{t=0}^{\infty}$, an (imperfectly) competitive equilibrium in the one-sector economy with sticky prices and durable consumption is a sequence $\left\{N_{t}, D_{t}, C_{t}, \pi_{t}\right\}_{t=0}^{\infty}$ solving (38) - (41). A Ramsey equilibrium in this economy can be obtained by maximizing $E_{0}\left\{\sum_{t=0}^{\infty} \beta^{t} U\left(C_{t}, D_{t}, N_{t}\right)\right\}$ subject to (38), (40) and (41). 


\section{B One (Final Good) Sector Economy}

Here we briefly describe the competitive equilibrium in the one-sector economy, featuring sticky prices, heterogenous patience rates, and borrowing constraints:

- borrower's efficiency condition on non-durable and durable consumption

$$
U_{c, t}=U_{d, t}+\beta(1-\delta) E_{t}\left\{U_{c, t+1}\right\}+U_{c, t}(1-\chi) \psi_{t}
$$

- deviation from Euler equation

$$
\psi_{t}=1-\beta E_{t}\left\{\frac{U_{c, t+1}}{U_{c, t}} \frac{R_{t}}{\pi_{t+1}}\right\}
$$

- Phillips curve

$$
\left(\pi_{t}-1\right) \pi_{t}=\gamma E_{t}\left\{\frac{\widetilde{U}_{c, t+1}}{\widetilde{U}_{c, t}}\left(\pi_{t+1}-1\right) \pi_{t+1}\right\}+A_{t} N_{t} \frac{\varepsilon}{\vartheta}\left(-\frac{U_{n, t}}{A_{t} U_{c, t}}-\frac{\varepsilon-1}{\varepsilon}\right)
$$

- resource constraint

$$
A_{t} N_{t}=C_{t}+D_{t}-(1-\delta) D_{t-1}+\frac{\vartheta}{2}\left(\pi_{t}-1\right)^{2}
$$

- borrower's flow budget constraint (with $T_{t}=0$ )

$$
C_{t}+q_{t}\left(D_{t}-(1-\delta) D_{t-1}\right)+\frac{R_{t-1} b_{t-1}}{\pi_{c, t}}=b_{t}+\frac{-U_{n, t}}{A_{t} U_{c, t}} N_{t}
$$

- saver's efficiency conditions 


$$
\begin{gathered}
\widetilde{U}_{c, t}=\gamma E_{t}\left\{\widetilde{U}_{c, t+1} \frac{R_{t}}{\pi_{t+1}}\right\} \\
\widetilde{U}_{c, t}=\widetilde{U}_{d, t}+\gamma(1-\delta) E_{t}\left\{\widetilde{U}_{c, t+1}\right\}
\end{gathered}
$$

For any policy sequence $\left\{R_{t}\right\}_{t=0}^{\infty}$ and stochastic process $\left\{A_{t}\right\}_{t=0}^{\infty}$, an (imperfectly) competitive equilibrium in the one-sector economy with sticky prices and borrowing constraints is a sequence $\left\{N_{t}, b_{t}, D_{t}, \widetilde{D}_{t}, C_{t}, \widetilde{C}_{t}, \pi_{t}\right\}$ solving (42) - (48).

\section{B.1 Recursive Ramsey Problem in the One-Sector Economy}

Let's define by $\Delta \equiv \beta^{\omega} \gamma^{1-\omega}$ the discount factor relevant from the viewpoint of the Ramsey planner problem, where $\omega$ is the weight attached on saver's utility. Below we describe the form of the optimal policy program in recursive form. This is necessary because the original problem is not time-invariant due to the fact that some constraints (such as (21)) exhibit future expectations of control variables. The recursive lagrangian problem in the economy with one final-good sector can be written as follows:

$$
\max E_{0} \sum_{t=0}^{\infty}\left(\left[(1-\omega) \beta^{t} U\left(C_{t}, D_{t}, N_{t}\right)+\omega \gamma^{t} U\left(\widetilde{C}_{t}, \widetilde{D}_{t}\right)\right]\right.
$$




$$
\begin{aligned}
& +\Delta^{t} \lambda_{1, t}\left[\left(U_{c, t}\left(1-(1-\chi) \psi_{t}\right)\right)-U_{d, t}\right]-\Delta^{t-1} \lambda_{1, t-1} \beta(1-\delta) U_{c, t} \\
& +\Delta^{t} \lambda_{2, t}\left[\left(\psi_{t}-1\right) \frac{U_{c, t}}{R_{t}}\right]+\Delta^{t} \lambda_{2, t-1} \frac{U_{c, t}}{\pi_{t}} \\
& +\Delta^{t} \lambda_{3, t}\left(\frac{U_{\widetilde{c}, t}}{R_{t}}\right)-\gamma \Delta^{t-1} \lambda_{3, t-1} \frac{U_{\widetilde{c}, t}}{\pi_{t}} \\
& +\Delta^{t} \lambda_{4, t}\left(A_{t} N_{t}-C_{t}-\widetilde{C}_{t}-D_{t}-\widetilde{D}_{t}-\frac{\vartheta}{2}\left(\pi_{t}-1\right)^{2}\right)+\Delta^{t+1} \lambda_{4, t+1}(1-\delta)\left(D_{t}+\widetilde{D}_{t}\right) \\
& +\Delta^{t} \lambda_{5, t}\left(b_{t}-(1-\chi) D_{t}\right) \\
& +\Delta^{t} \lambda_{6, t}\left(C_{t}+D_{t}+\frac{R_{t-1} b_{t-1}}{\pi_{t}}-b_{t}+\frac{U_{n, t}}{U_{c, t}} N_{t}\right)-\Delta^{t} \lambda_{6, t+1}\left((1-\delta) D_{t}+\frac{R_{t} b_{t}}{\pi_{t+1}}\right) \\
& +\Delta^{t} \lambda_{7, t}\left(\widetilde{U}_{c, t}-\widetilde{U}_{d, t}\right)-\gamma \Delta^{t-1} \lambda_{7, t-1}(1-\delta) \widetilde{U}_{c, t} \\
& \left.+\left(\Delta^{t} \lambda_{8, t}-\gamma \Delta^{t-1} \lambda_{8, t-1}\right)\left(\widetilde{U}_{c, t}\left(\pi_{t}-1\right) \pi_{t}\right)-\Delta^{t} \lambda_{8, t} \frac{\varepsilon A_{t} N_{t}}{\vartheta}\left(\frac{-U_{n, t}}{A_{t} U_{c, t}}-\mu^{-1}\right)\right)
\end{aligned}
$$

where $\mu \equiv \frac{\varepsilon}{\varepsilon-1}$ is the steady state markup and $\pi_{t}$ is final good inflation. This maximization program is recursive saddle-point stationary in the amplified state space $\left\{A_{t}, Z_{t}\right\}$, where $Z_{t} \equiv\left\{\lambda_{1, t-1}, \lambda_{2, t-1}, \lambda_{3, t-1}, \lambda_{7, t-1}, \lambda_{8, t-1}\right\}$. The corresponding (log-linearized) set of first order conditions describe a time-invariant system of difference equations to the extent that the initial condition $Z_{0}=\bar{Z} \equiv\left[\bar{\lambda}_{1}, \bar{\lambda}_{2}, \bar{\lambda}_{3}, \bar{\lambda}_{7}, \bar{\lambda}_{8},\right]$ is added, where $\bar{\lambda}_{j}$ denotes the steady state value of multiplier $\lambda_{j}$, for $j=1,2,3,7,8$.

\section{Recursive Ramsey Problem in the Two-Sector Econ- omy}

The recursive lagrangian for the Ramsey problem in the two sector economy can be written

$$
\max E_{0} \sum_{t=0}^{\infty}\left(\left[(1-\omega) \beta^{t} U\left(C_{t}, D_{t}, N_{t}\right)+\omega \gamma^{t} U\left(\widetilde{C}_{t}\right)\right]\right.
$$




$$
\begin{aligned}
& +\Delta^{t} \lambda_{1, t}\left[\left(q_{t} U_{c, t}\left(1-(1-\chi) \psi_{t}\right)\right)-U_{d, t}\right]-\Delta^{t-1} \lambda_{1, t-1} \beta(1-\delta) q_{t} U_{c, t} \\
& +\Delta^{t} \lambda_{2, t}\left[\left(\psi_{t}-1\right) \frac{U_{c, t}}{R_{t}}\right]+\Delta^{t} \lambda_{2, t-1} \frac{U_{c, t}}{\pi_{c, t}} \\
& +\Delta^{t} \lambda_{3, t}\left(\frac{U_{\widetilde{c}, t}}{R_{t}}\right)-\gamma \Delta^{t-1} \lambda_{3, t-1} \frac{U_{\widetilde{c}, t}}{\pi_{c, t}} \\
& +\Delta^{t} \lambda_{4, t}\left(A_{c, t} N_{c, t}-C_{t}-\widetilde{C}_{t}-\frac{\vartheta_{c}}{2}\left(\pi_{c, t}-1\right)^{2}\right) \\
& +\Delta^{t} \lambda_{5, t}\left(b_{t}-(1-\chi) D_{t} q_{t}\right) \\
& +\Delta^{t} \lambda_{6, t}\left(C_{t}+q_{t} D_{t}+\frac{R_{t-1} b_{t-1}}{\pi_{c, t}}-b_{t}+\frac{U_{n, t}}{U_{c, t}} N_{t}\right)-\Delta^{t} \lambda_{6, t+1}\left((1-\delta) D_{t} q_{t+1}+\frac{R_{t} b_{t}}{\pi_{c, t+1}}\right) \\
& +\Delta^{t} \lambda_{7, t}\left(q_{t} \widetilde{U}_{c, t}-\widetilde{U}_{d, t}\right)+\Delta^{t-1} \lambda_{7, t-1}\left(-\gamma(1-\delta) \widetilde{U}_{c, t} q_{t}\right) \\
& +\left(\Delta^{t} \lambda_{8, t}-\gamma \Delta^{t-1} \lambda_{8, t-1}\right)\left(\widetilde{U}_{c, t}\left(\pi_{c, t}-1\right) \pi_{c, t}\right)-\Delta^{t} \lambda_{8, t} \frac{\varepsilon_{c} A_{c, t} N_{c, t}}{\vartheta_{c}}\left(\frac{-U_{n, t}}{A_{c, t} U_{c, t}}-\mu_{c}^{-1}\right) \\
& +\left(\Delta^{t} \lambda_{9, t}-\gamma \Delta^{t-1} \lambda_{9, t-1}\right)\left(q_{t} \widetilde{U}_{c, t}\left(\pi_{d, t}-1\right) \pi_{d, t}\right)-\Delta^{t} \lambda_{9, t} \frac{\varepsilon_{d} A_{d, t} N_{d, t}}{\vartheta_{d}}\left(\frac{-U_{n, t}}{A_{d, t} U_{c, t} q_{t}}-\mu_{d}^{-1}\right) \\
& +\Delta^{t} \lambda_{10, t}\left(A_{d, t} N_{d, t}-D_{t}-\widetilde{D}_{t}-\frac{\vartheta_{d}}{2}\left(\pi_{d, t}-1\right)^{2}\right)+\Delta^{t+1} \lambda_{10, t+1}(1-\delta)\left(D_{t}+\widetilde{D}_{t}\right) \\
& +\Delta^{t} \lambda_{11, t}\left(N_{t}-N_{c, t}-N_{d, t}\right) \\
& +\Delta^{t} \lambda_{12, t}\left(\frac{\pi_{d, t}}{\pi_{c, t} q_{t}}\right)-\Delta^{t+1} \lambda_{12, t+1} q_{t+1}^{-1}
\end{aligned}
$$

This maximization program is recursive saddle-point stationary in the amplified state space $\left\{A_{c, t}, A_{d, t}, Z_{t}^{\prime}\right\}$, where $Z_{t}^{\prime} \equiv\left\{\lambda_{1, t-1}, \lambda_{2, t-1}, \lambda_{3, t-1}, \lambda_{7, t-1}, \lambda_{8, t-1}, \lambda_{9, t-1}\right\}$ and with the initial condition $Z_{0}^{\prime}=\bar{Z}^{\prime}$. 


\section{References}

[1] Adao, B., Correia, I., P. Teles, (2003), "Gaps and Triangles", Review of Economic Studies, 60, 4.

[2] Aoki A. (2001), "Optimal Monetary Policy Responses to Relative Price Changes", Journal of Monetary Economics 48: 55-80.

[3] Aizcorbe, A. A. Kennickell, K. Moore (2003), "Recent Changes in U.S. Family Finances: Evidence from the 1998 and 2001 Survey of Consumer Finances", Federal Reserve Bullettin, 89, 1-32.

[4] Atkinson, A. B. and J. Stiglitz, (1976), "The Design of Tax Structure: Direct Versus Indirect Taxation", Journal of Public Economics, 6, 1-2, 55-75

[5] Barski R., C. House and M. Kimball (2004), " Sticky Price Models and Durable Goods", Mimeo University of Michigan.

[6] Becker R. (1980), "On the Long-Run Steady State in a Simple Dynamic Model of Equilibrium with Heterogenous Agents", Quarterly Journal of Economics, Vol. 95, No 2, pp. 375-382.

[7] Becker R. and C. Foias (1987), "A Characterization of Ramsey Equilibrium", Journal of Economic Theory, 41, 173-84.

[8] Benigno, P. and M. Woodford (2005), "Inflation Stabilization and Welfare: The Case of a Distorted Steady State", forthcoming Journal of the European Economic Association.

[9] Bernanke, B., M. Gertler, (1989)," Agency Costs, Net Worth and Business Fluctuations", American Economic Review, March, 14-31.

[10] Bernanke, B., M. Gertler and S. Gilchrist, (1999), "The Financial Accelerator in a Quantitative Business Cycle Framework", in J.B. Taylor, and M. Woodford, eds., Handbook of Macroeconomics, Amsterdam: North-Holland. 
[11] Bernanke, B., M. Gertler, (2001), "Should Central Banks Respond to Movements in Asset Prices?" American Economic Review Papers and Proceedings, 91 (2), 253-257.

[12] Bils M. and P. Klenow (2004), "Some Evidence on the Importance of Sticky Prices", Journal of Political Economy, October.

[13] Calza A., T.Monacelli and L.Stracca (2006), "Mortgage Markets, Collateral Constraints and Monetary Policy: Do Institutional Factors Matter?", Mimeo, European Central Bank and Università Bocconi.

[14] Campbell J. Y. and G. Mankiw (1989), "Consumption, Income and Interest Rates: Reinterpreting the Time Series Evidence", NBER Macroeconomics Annual, MIT Press.

[15] Campbell J. and Z. Hercowitz (2005), "The Role of Collateralized Household Debt in Macroeconomic Stabilization", NBER w.p 11330.

[16] Chari, V.V., L. J. Christiano and P.J. Kehoe (1991), "Optimal Fiscal and Monetary Policy: Some Recent Results", Journal of Money, Credit and Banking, 23:519 539.

[17] Clarida, R., J. Galí, and M. Gertler (1999): "The Science of Monetary Policy: A New Keynesian Perspective," Journal of Economic Literature, vol. 37, 1661-1707.

[18] Erceg C. and A. Levin, (2005), "Optimal Monetary Policy with Durable Consumption Goods", International Finance Discussion Paper 748, Board of Governors.

[19] Galí J. (1999), "Technology, Employment, and the Business Cycle: Do Technology Schocks Explain Aggregate Fluctuations?", American Economic Review, 249, 271.

[20] Galí J., D. Lopez-Salido and J. Valles (2003), "Understanding the Effects of Government Spending on Consumption", forthcoming Journal of the European Economic Association.

[21] Goodfriend, M. and R. King, (1997), "The New Neoclassical Synthesis", NBER Macroeconomics Annual. 
[22] Iacoviello, M. (2005), "House Prices, Borrowing Constraints and Monetary policy in the Business Cycle", American Economic Review.

[23] Jappelli T. and M. Pagano (1989), "Consumption and Capital Markets Imperfections: an International Comparison", American Economic Review, vol. 79, pp. 1088-1105.

[24] Khan, A., R. King and A.L. Wolman, (2003), "Optimal Monetary Policy", Review of Economic Studies, 60,4.

[25] King R. and S. Rebelo, (1999), "Resuscitating Real Business Cycles," in J.B. Taylor, and M. Woodford, eds., Handbook of Macroeconomics, Amsterdam: North-Holland.

[26] King, R. and A. L. Wolman, (1999), "What Should the Monetary Authority Do When Prices Are Sticky", in Taylor, J. B., ed., Monetary Policy Rules, Chicago: university of Chicago Press, 349-398.

[27] Kiyotaki, N. and J. Moore, (1997), "Credit Cycles", Journal of Political Economy, 105, April , 211-48.

[28] Krusell P. and A. Smith (1998), "Income and Wealth Heterogeneity in the Macroeconomy", Journal of Political Economy, 106, 867-896.

[29] Kydland, F. and E. C. Prescott, (1980), "Dynamic Optimal Taxation, Rational Expectations and Optimal Control", Journal of Economic Dynamics and Control, 2:7991.

[30] Lucas, R. E. and N. Stokey, (1983), "Optimal Fiscal and Monetary Policy in an Economy Without Capital", Journal of Monetary Economics, 12:55-93.

[31] Monacelli, Tommaso (2005), "New Keynesian Models, Durable Goods and Borrowing Constraints", unpublished.

[32] Monacelli, Tommaso (2006), "Productivity Shocks, Employment and Durable Goods", unpublished. 
[33] Ramsey, F. P., (1927), "A contribution to the Theory of Taxation", Economic Journal, 37:47-61.

[34] Rotemberg, J. and M. Woodford, (1997), "An Optimization-Based Econometric Model for the Evaluation of Monetary Policy", NBER Macroeconomics Annual, 12: 297-346.

[35] Schmitt-Grohe, S. and M. Uribe (2004), "Optimal Fiscal and Monetary Policy under Sticky Prices", Journal of Economic Theory, 114,198-230.

[36] Schmitt-Grohe, S. and M. Uribe (2005), "Optimal Inflation Stabilization in a Medium-Scale Macroeconomic Model", mimeo.

[37] Siu, H. (2004) "Optimal Fiscal and Monetary Policy with Sticky Prices", Journal of Monetary Economics 51(3), April.

[38] Stock J. and M. Watson (2002), "Has the Business Cycle Changed and Why?", NBER Macroeconomics Annual, 159-218, MIT Press.

[39] Woodford, Michael (2003), Interest and Prices: Foundations of a Theory of Monetary Policy, Princeton University Press.. 